\title{
Dissection of Two Complex Clusters of Resistance Genes in Lettuce (Lactuca sativa)
}

\author{
Marilena Christopoulou, Leah K. McHale, Alex Kozik, Sebastian Reyes-Chin Wo, Tadeusz Wroblewski, \\ and Richard W. Michelmore
}

Genome Center and Department of Plant Sciences, University of California-Davis, CA 95616, U.S.A.

Submitted 21 June 2015. Accepted 28 January 2015.

\begin{abstract}
Of the over 50 phenotypic resistance genes mapped in lettuce, 25 colocalize to three major resistance clusters (MRC) on chromosomes 1, 2, and 4. Similarly, the majority of candidate resistance genes encoding nucleotide binding-leucine rich repeat (NLR) proteins genetically colocalize with phenotypic resistance loci. MRC1 and MRC4 span over 66 and $63 \mathrm{Mb}$ containing 84 and 21 NLR-encoding genes, respectively, as well as 765 and 627 genes that are not related to NLR genes. Forward and reverse genetic approaches were applied to dissect MRC1 and MRC4. Transgenic lines exhibiting silencing were selected using silencing of $\beta$-glucuronidase as a reporter. Silencing of two of five NLR-encoding gene families resulted in abrogation of nine of 14 tested resistance phenotypes mapping to these two regions. At MRC1, members of the coiled coilNLR-encoding $R G C 1$ gene family were implicated in host and nonhost resistance through requirement for $\mathrm{Dm} 5 / 8$ - and $\mathrm{Dm} 45$ mediated resistance to downy mildew caused by Bremia lactucae as well as the hypersensitive response to effectors AvrB, AvrRpm1, and AvrRpt2 of the nonpathogen Pseudomonas syringae. At MRC4, RGC12 family members, which encode toll interleukin receptor-NLR proteins, were implicated in $\mathrm{Dm} 4$-, Dm7-, Dm11-, and Dm44-mediated resistance to B. lactucae. Lesions were identified in the sequence of a candidate gene within $d m 7$ loss-of-resistance mutant lines, confirming that $R G C 12 G$ confers Dm7.
\end{abstract}

Plants contain multiple phenotypic resistance $(R)$ genes that provide resistance to diverse pathogens and pests. The majority of genes involved in pathogen recognition identified to date encode nucleotide binding and leucine-rich repeat (NLR) proteins (Glowacki et al. 2011; Liu et al. 2007; Lukasik and Takken 2009). The presence of shared characteristic motifs among cloned $R$ genes has facilitated the identification of numerous candidate resistance genes (Sharma et al. 2009). Sequences with similarity to cloned $R$ genes are usually clustered in plant genomes and often cosegregate with multiple resistance specificities (Dodds and Rathjen 2010; McHale et al.

M. Christopoulou and L. K. McHale contributed equally to this work.

Current address for L. K. McHale: Department of Horticulture and Crop Science, The Ohio State University, Columbus, OH 43210, U.S.A.

Corresponding author: R. Michelmore;

E-mail: rwmichelmore@ucdavis.edu

*The $\boldsymbol{e}$-Xtra logo stands for "electronic extra" and indicates that six supplementary figures and five supplementary tables are published online.

○ 2015 The American Phytopathological Society
2006). The cloning of $R$ genes not only furthers our understanding of the molecular basis of disease resistance but also has significant practical implications to breeding programs by providing robust markers for marker-assisted selection and enabling pyramiding of $R$ genes.

The plant defense system consists of several layers of defense (Chisholm et al. 2006; Katagiri and Tsuda 2010). Patternrecognition receptors, localized in the plasma membrane, can detect conserved pathogen molecular patterns such as chitin or flagellin and trigger broad-spectrum basal resistance (Boller and Felix 2009; Monaghan and Zipfel 2012). Pathogens have developed mechanisms to suppress basal defenses by delivering effector proteins inside host cells (Feng and Zhou 2012; Rafiqi et al. 2012). In response, plants have evolved intracellular NLR receptors that can detect the effector molecules in a direct or indirect manner and elicit potent defense responses (effectortriggered immunity [ETI]), which oftentimes involve programmed cell death characteristic of the hypersensitive response (HR) (Jones and Dangl 2006; McHale et al. 2006). During direct recognition, NLR receptors interact directly with pathogen effectors. During indirect recognition, they act as guards monitoring the status of other plant proteins targeted by effectors (Jones and Dangl 2006). NLR are modular proteins that consist of an N-terminal domain, a conserved central nucleotide-binding ARC domain (NB-ARC), similar to the one found in the mammalian NOD protein apoptotic protease activating factor and Caenorhabditis elegans cell death proteins, and a highly variable C-terminal domain encoding multiple leucine-rich repeats (LRR) (Takken and Goverse 2012; Tameling and Takken 2008). NLR proteins can be divided into two major types, TNL or CNL, based on whether they have toll interleukin receptor (TIR) or coiled-coil (CC) N-terminal domains that are implicated in downstream signaling (Nandety et al. 2013; Qi et al. 2012). Phylogenetic analysis of the conserved NB-ARC domain reveals two major types within the superfamily of NLR proteins, each characteristic of either TNL or CNL proteins (McHale et al. 2006; Meyers et al. 2003). Families of NLR-encoding genes are greatly expanded across the plant kingdom, and generally, hundreds are present in each genome (Guo et al. 2011; Tamura and Tachida 2011; Yue et al. 2012).

Lettuce is one of the most valuable vegetable crops in the United States with value of approximately $\$ 2$ billion per annum, $80 \%$ of which is produced in California (National Agricultural Statistical Service 2013). Lettuce downy mildew (DM), caused by the oomycete Bremia lactucae Regel, is the most devastating foliar disease affecting lettuce production in the United States and worldwide. The pathogen can cause severe epidemics under favorable environmental conditions, rendering the crop unmarketable (Davis et al. 1997). The 
development of DM-resistant cultivars is a major focus of most lettuce-breeding programs (Crute 1989). B. lactucae is an obligate biotroph that interacts with lettuce in a gene-for-gene manner and is a model system for the study of plant-pathogen interactions (Crute 1992; Michelmore et al. 2009). More than 25 genes for resistance to downy mildew $(\mathrm{Dm})$ have been identified that confer race-specific resistance to B. lactucae; the majority are dominant genes that elicit strong HR upon the recognition of the cognate avirulence factor in a gene-for-gene manner (Crute and Johnson 1976; Farrara et al. 1987; Ilott et al. 1989; Michelmore and Wong 2008; Michelmore et al. 2009). Numerous Dm genes have been introgressed from wild Lactuca spp., particularly L. serriola, the likely progenitor of cultivated L. sativa (Crute 1992). However, resistance has often been overcome soon after deployment, due to the rapid emergence of virulent isolates and the widespread aerial dispersal of new pathotypes.

Several genetic and genomic resources and tools are now available for lettuce, enabling detailed genetic and functional analyses. Many important agricultural traits have been aligned in a single integrated genetic map (Truco et al. 2007). This facilitated a global analysis of disease resistance genes in lettuce. A total of 291 genes involved in disease resistance were mapped relative to 36 phenotypic resistance loci for seven different diseases and two pests; 34 of the 36 resistance phenotypes analyzed cosegregated with defense-related genes (McHale et al. 2009). An ultrahigh density genetic map, developed using recombinant inbred lines from $L$. sativa $\mathrm{cv}$. Salinas $\times$ L. serriola accession US96UC23, comprises 12,841 mapped unigenes in nine chromosomal linkage groups (Truco et al. 2013). Comparative studies of the genetic diversity between cultivars revealed five regions of elevated polymorphism in L. sativa that corresponded to the five clusters of NLR encoding genes on linkage groups $1,2,3,4$, and 8 resulting from introgression of resistant alleles from wild germplasm (McHale et al. 2009; Michelmore et al. 2010). Recently, a draft reference genome has been generated for $L$. sativa cv. Salinas that captures the majority of the NLR-encoding genes as well as a genetic map that assigns $96 \%$ of the assembled genome to genetic bins ordered along the nine chromosomal linkage groups (unpublished data).

Of the five MRC in lettuce, MRC2 on chromosome 2 has been most extensively studied. MRC2 is comprised of eight $D m$ genes, resistance to root aphid ( $R a)$ (Ellis et al. 2002), a quantitative trait locus (QTL) for resistance to anthracnose (ANT1) (McHale et al. 2009), and 15 to 42 colocalized members of the Resistance Gene Candidate 2 (RGC2) family of CNL (Kuang et al. 2004; Shen et al. 2002), as well as several NLR outside the $R G C 2$ family (McHale et al. 2009). A complex evolutionary history that apparently has included mutation, gene conversion, and recombination has resulted in numerous variants of the members of the $R G C 2$ family being distributed within and among Lactuca spp. accessions (Kuang et al. 2004). Map-based cloning and analysis of deletion mutants identified that $R G C 2 B$ confers $D m 3$ (Shen et al. 2002). Transformation and silencing with a hairpin RNA interference (RNAi) construct derived from $R G C 2 B$ abrogated the resistance mediated by $D m 14, D m 16, D m 18$, and $R a$, indicating that these MRC2 genes are also encoded by $R G C 2$ family members (Wroblewski et al. 2007). However, it remains time-consuming to identify the sequences that determine individual resistance phenotypes and no additional genes have been cloned.

MRC1 and MRC4 had been less well studied than MRC2. $\mathrm{MRC} 1$ on chromosome 1 is comprised of four $\mathrm{Dm}$ genes $(\mathrm{Dm} 5 / 8$, Dm10, Dm43, Dm36) (Hulbert and Michelmore 1985; Landry et al. 1987), a QTL for resistance to downy mildew (RBQ2)
(Jeuken and Lindhout 2002), resistance to lettuce mosaic virus (Mo2) (Nicaise et al. 2003), resistance to Turnip mosaic virus (Robbins et al. 1994), recessive resistance to Plasmopara lactucae-radicis (Witsenboer et al. 1995), and the HR elicited in response to the Pseudomonas syringae effector proteins AvrB, AvrRpt2, and AvrRpm1 (AvrB-HR, AvrRpt2-HR, AvrRpm1-HR) (Wroblewski et al. 2009). Dm17 mapped to a single locus but was positioned within a broad $(36 \mathrm{cM})$ interval on linkage group 1 of the consensus genetic map (Maisonneuve et al. 1994). Since the early 1930s, three sources have been reported for the introgression of Dm5/8: old L. sativa cultivars such as Sucrine and Bourguignonne Grosse Blonde d'Hiver, L. serriola PI167150 (for cv. Valmaine along with Dm10), and L. serriola PI91532 (for cvs. Salinas and Diana) (Witsenboer et al. 1995). Dm5/8 resistance from these different sources is phenotypically and genetically indistinguishable; however, marker analysis revealed at least two haplotypes for $\mathrm{Dm} 5 / 8$ (Witsenboer et al. 1995). Expressed sequence tag (EST)-based mapping studies showed both TNL (RGC16 members) and CNL ( $R G C 1$ members) are located within the MRC1 region (McHale et al. 2009). MRC4 spans approximately $25 \mathrm{cM}$ of linkage group 4 and is comprised of four downy mildew resistance loci (Dm4,Dm7,Dm11, and Dm44) (Hulbert and Michelmore 1985; Landry et al. 1987). $D m 7$ was introgressed from the European cv. Romain Blonde Lente a Monter into the majority of the cultivars used in the United States from the 1930 s to the early 1960 s and is common in commercial lines currently used (Crute 1992). Loss-of-resistance mutants for $D m 7$ have been previously isolated from cv. Diana (Chin et al. 2001).

This paper describes the analysis of MRC1 and MRC4 to determine the genes or gene families encoding $D m$ resistance phenotypes and HR to effector proteins. When this work was initiated in 2004, fragments of 18 NLR EST had been mapped genetically within MRC1 or MRC4. To associate gene sequences with one or both resistance or HR, we generated and analyzed transgenic RNAi tester stocks expressing small interfering RNAs (siRNAs) derived from representative NLR. In addition, we identified genomic lesions in $d m 7$ loss-ofresistance mutant lines. These experiments led to the identification of the gene families responsible for five $\mathrm{Dm}$ genes and the HR responses to three effector proteins as well as the gene likely encoding $D m 7$. During the course of this work, ultradense genetic maps, a draft reference genome sequence for L. sativa cv. Salinas, and preliminary genome assemblies for cvs. Diana and Valmaine became available. Based on these new genetic and genomic resources, we have expanded our understanding of the genomic landscape to include 84 and 21 NLR in MRC1 and MRC4, respectively, that are embedded in hundreds of other non-NLR genes, each spanning approximately $65 \mathrm{Mb}$.

\section{RESULTS}

\section{Analyses of MRC1.}

MRC1 on chromosome 1 contains numerous NLR-encoding sequences in L. sativa cv. Salinas. The availability of the lettuce genome ( $L$. sativa $\mathrm{cv}$. Salinas) enabled detailed characterization of the genomic architecture of the MRC1 locus. Mining a comprehensive dataset of 39,000 gene models for the presence of characteristic Pfam domains (Lettuce Genome Resource) identified 385 gene models with an NB-ARC domain (with and without the presence of CC, TIR, and LRR domains), 40 gene models encoding TIR domains (no additional domains), and 687 LRR-encoding genes (with or without a kinase domain) (unpublished data). This was used as the reference set of putative NLR-encoding genes in lettuce described in this paper. 
MRC1 as defined by the presence of NLR genes spans a large genomic region (approximately $62 \mathrm{Mb}$ ) in chromosome 1 . It contains 124 scaffolds of approximately $54.3 \mathrm{Mb}$ in length and a total of 857 genes (Fig. 1). A large number (52\%) of these genes have no assigned function. There was significant enrichment for genes annotated with terms related to pathogen defense response and signal transduction (Table 1). This enrichment was attributed to the NLR genes; upon their exclusion, only protein phosphorylation was significantly enriched (Table 1). Of the 765 genes in MRC1 that do not code for NLR proteins, 11 have predicted functions in disease resistance or response to abiotic stress. There are 84 putative NLR-encoding genes in MRC1, $20 \mathrm{CNL}$ and $64 \mathrm{TNL}$ found in clusters (Table 2; Fig. 1). Members of five NLR-encoding gene families (RGC1, RGC6, RGC31, RGC14, and RGC16) are present, as identified by the phylogenetic clustering of 385 NLR into 42 NLR families in the lettuce genome (unpublished). In particular, the RGC16 family is greatly expanded within MRC1, with 62 genes (Table 3). Members of the same NLR family tend to be located adjacent to each other (Fig. 1).

$N L R$ content within the MRC1 region has varying levels of conservation across three additional lettuce genotypes. The MRC1 regions in L. sativa cvs. Diana and Valmaine and L. serriola accession US96UC23 were compared with that of cv. Salinas. The genome assemblies of the three additional genotypes were mined for the presence or absence and level of sequence diversity of NLR-encoding genes within MRC1 (Supplementary Table S3). Presence was confirmed with best reciprocal blast hits for genes with $>89 \%$ sequence identity across the entire length of each coding sequence. The draft assemblies of these three genotypes are more fragmented than the reference sequence of cv. Salinas, preventing detailed syntenic comparisons across this locus; however, several pairs of NLR-encoding genes located within $200 \mathrm{~kb}$ in cv. Salinas were also found to be colocated at approximately the same distances in the other three assemblies. NLR genes from cvs. Diana and Salinas shared high sequence identity, as expected since Dm5/8 was introgressed from the same progenitor (Witsenboer et al. 1995); the average percentage of identity for homologous pairs between cv. Diana and Salinas was $99 \%$ for 76 out of 84 NLR in MRC1. The remaining eight NLR present in cv. Salinas were not detected in cv. Diana. Only 56 of 84 NLR from MRC1 in cv. Salinas were detected in cv. Valmaine, which has $D m 5 / 8$ from a different source, and the average level of sequence identity between homologous NLR pairs from cv. Salinas and Valmaine $(97.1 \%$ ) was slightly smaller than that of homologous NLR pairs from cvs. Salinas and Diana. The NLR in accession US96UC23 of the wild L. serriola were slightly more diverse, with $96.3 \%$ identity for 59 NLR of MRC1.

Silencing using RNAi results in the loss of multiple resistance specificities within MCR1. Sixteen NLR (Table 4; Supplementary Table S1; Supplementary Fig. S1), including QGF20G21 and $Q G F 16 M 04$, which had been previously mapped within MRC1 (McHale et al. 2009), were selected for further analysis using RNAi. Stable RNAi tester stocks were generated and crossed as necessary to test for their silencing of $D m 5 / 8$ (in Diana), Dm10 (in UCDM10), Dm36 (in Ninja), Dm17 (in L. serriola accession LSE102), Dm43 (in accession 09G1123), Dm45 (in accession 09G952), and HR elicited by the effector proteins AvrB, AvrRpm1, and AvrRpt2 of P. syringae (in Ninja) (Tables 4 and 5). The inclusion of a DNA fragment from the $\beta$-glucuronidase (GUS) reporter gene concatenated with the NLR trigger sequence in the hairpin siRNA construct allowed the monitoring of silencing in primary transformants and segregating progeny using Agrobacterium-mediated transient assays of GUS activity (Wroblewski et al. 2007). On average $15 \mathrm{~T}_{2}$ or $F_{1}$ plants were tested for each self-pollination or cross. The siRNA transgene segregated in the expected $3: 1$ or $1: 1$ ratios as detected by both polymerase chain reaction (PCR) and the transient GUS expression assays (Fig. 2). There was a complete correlation between silencing of GUS and the presence of the transgene.

Two transgenic lines that had silenced $G U S$ were identified and tested for each transformation event (Table 4). The two $\mathrm{T}_{1}$ QGF20G21_LRR_RNAi Diana lines silenced for QGF20G21 (siDiana-QGF20G21_LRR) and challenged with $B$. lactucae isolate CG1 showed a loss of the resistance conferred by $D m 5 / 8$ but remained resistant to isolates C83M47 (Avrl), AM (Avr3), and R60 (Avr7). Therefore, the loss of resistance was specific to $D m 5 / 8$ rather than a generic loss of $D m$ activity (Table 4). Loss of $D m 5 / 8$ resistance was confirmed in the $\mathrm{T}_{2}$ generation and cosegregated with lack of GUS activity in transient assays, indicating that $D m 5 / 8$ in the Diana background was conferred by $Q G F 20 G 21$ or a closely related gene or genes. Because

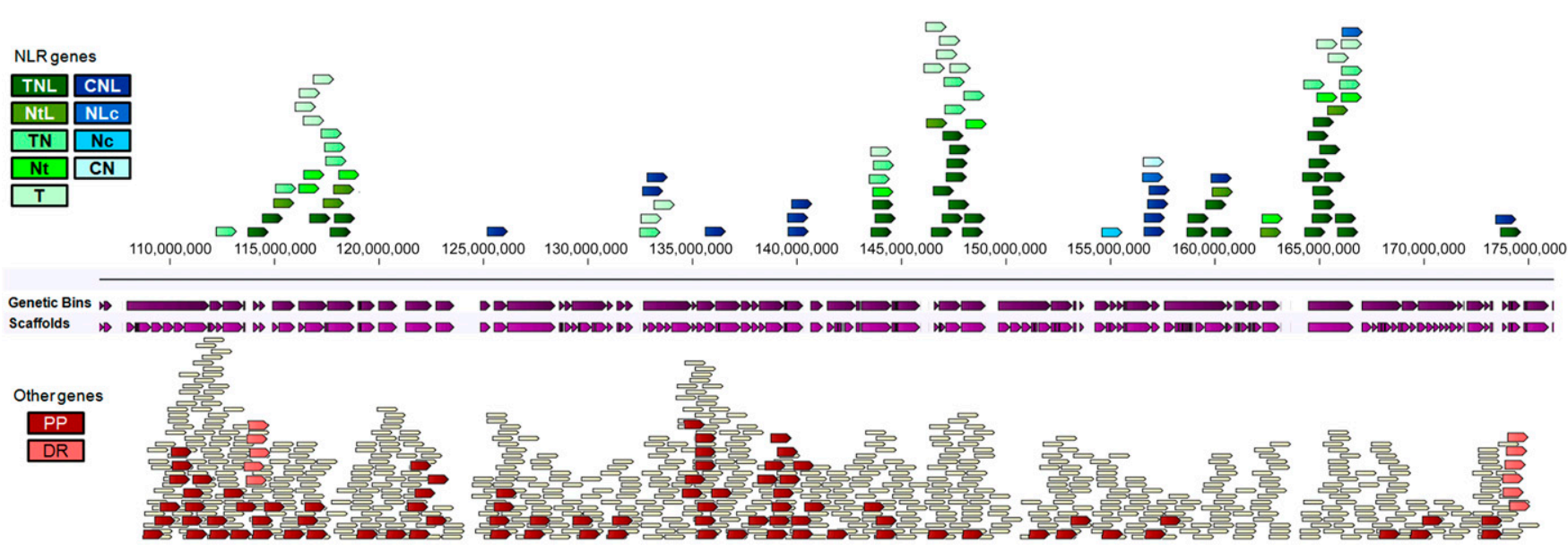

Fig. 1. Graphical overview of the major resistance cluster on chromosome 1 (MRC1). The top panel shows the nucleotide binding (NB)-leucine rich repeat (NLR)-encoding genes mapped relative to the scaffolds and the genetic bins of the reference genome assembly of Lactuca sativa cv. Salinas (Lsat.1.v6.1g), whereas the bottom panel shows all other genes that map to this locus. The genes are color-coded: TNL (N-terminal domains with toll interleukin receptors [TIR]) are shown in shades of green and CNL (coiled-coil [CC] terminal domains) in shades of blue, other genes involved in defense response (DR) genes are in pink, protein phosphorylation (PP) in red, and the remainder of the genes in yellow. The NLR are subdivided into different groups based on the number of domains detected. Lower case letters are used when the domain itself is not present but inferred based on the phylogeny of the NB domain. 
Dm5/8 has been introgressed from multiple sources, the effect of QGF20G21_LRR_RNAi was evaluated in cv. Valmaine in addition to cv. Diana (Dm5/8 introgressed from L. serriola PI167150 and PI91532, respectively) (Witsenboer et al. 1995). The loss of Dm5/8 resistance and the lack of GUS expression cosegregated in $\mathrm{F}_{1}$ plants of Valmaine $\times$ siDiana-QGF20G21_LRR. Therefore Dm5/8 originating from both PI81532 and PI67150 is conferred by one or more members of the same CNL family.

$\mathrm{F}_{1}$ plants of UCDM10 $\times$ siDiana-QGF20G21_LRR also cosegregated for the loss of $D m 5 / 8$ resistance and the lack of GUS expression. However, challenge with isolate C83M47 revealed no loss of resistance conferred by $\mathrm{Dm} 10$. Similarly, no change in Dm36 resistance was observed in the GUS-silenced $\mathrm{T}_{2}$ progeny of cv. Ninja transformed with QGF20G21_LRR_RNAi (siNinja-QGF20G21_LRR) (Table 4). An HR response was observed in all $\mathrm{T}_{2}$ progeny of siNinja-QGF20G21_LRR after infiltration with Agrobacterium strains expressing AvrB, AvrRpm1, or AvrRpt 2 effectors. Therefore, there was no evidence that $D m 10$, Dm36, or the HR elicited by AvrB, AvrRpm1, and AvrRpt2 were conferred by $Q G F 20 G 21$ or a closely-related gene.

Two transgenic lines silenced for $G U S$ were identified for cv. Cobham Green transformed with QGF16M04_LRR_RNAi and were crossed to six genotypes carrying nine different resistance phenotypes (Table 4). All $\mathrm{F}_{1}$ plants tested retained their resistance mediated by $D m 17, D m 10, D m 36$, and $D m 43$, regardless of the presence of the silencing transgene. Therefore, there was no evidence that QGF16M04 confers Dm17-, Dm10-, Dm36-, or Dm43- mediated resistance (Table 4). The Valmaine $\times$ siCobham Green-QGF16M04_LRR and accession 09G952 $\times$ siCobham Green-QGF16M04_LRR hybrids showed a loss of Dm5/8- and Dm45-mediated resistances, respectively, which cosegregated with the transgene, indicating that $Q G F 16 M 04$ or a highly similar gene is required for both the $D m 5 / 8$ - and $D m 45$ mediated resistance phenotypes (Table 4). Abrogation of the HR for $P$. syringae effectors AvrB, AvrRpm1, and AvrRpt2 cosegregated with silencing of GUS in Ninja $\times$ siCobham GreenQGF16M04_LRR $F_{1}$ hybrids (Table 4), while a strong HR was still observed for AvrPto that served as a positive control for HR (Supplementary Table S5). Therefore, QGF16M04 or a CNL gene with high sequence similarity is required for $D m 5 / 8$ and Dm45 as well as the HR elicited by the effectors AvrB, AvrRpm1, and AvrRpt2.

The remaining 14 RNAi tester stocks elicited no loss of resistance for all the phenotypes tested despite robust silencing of
GUS. Therefore, there was no evidence that their source genes confer any of the resistance phenotypes for which they were tested.

Comparative analysis of the RGC1 family in cvs. Salinas, Diana, and Valmaine identified candidate genes for Dm5/8. Results from RNAi experiments indicated that one or both QGF16M04 or QGF20G21 genes or other closely related sequences are required for the $D m 5 / 8$-mediated resistance. Both of these genes belong to the $R G C 1$ family and, therefore, the $17 R G C 1$ genes that map to MRC1 were possible candidates for $D m 5 / 8$ (Fig. 3). Previous work (Wroblewski et al. 2007) showed that quantitative (q)PCR was not conclusively informative for demonstrating silencing of specific NLR genes whose high sequence homology and low levels of expression limit the accuracy and usefulness of qPCR. Therefore, we used the genome assemblies for L. sativa cvs. Diana and Valmaine and for the closely related weedy progenitor $L$. serriola accession US96UC23 to test, in silico, which genes could be potential targets for each of the RNAi constructs, based on sequence identity (Table 6). Potential $R G C l$ targets of both of these silencing constructs were identified in cvs. Salinas, Diana, and Valmaine that carry the $D m 5 / 8$ specificity, by sequence identity to the trigger sequences (Table 6). Four $R G C 1$ genes were identified as being targeted in both Valmaine and Diana by QGF16M04_LRR_RNAi and QGF20G21_LRR_RNAi, but only three of the four showed evidence of expression (Fig. 3; Table 6). Therefore, these four genes are the most likely candidate genes for $\mathrm{Dm} 5 / 8$.

\section{Analyses of MRC4.}

MRC4 contains numerous NLR-encoding genes in $\mathrm{cv}$. Salinas. MRC4 is an approximately 25 -cM region of chromosomal linkage group 4. It contains 124 scaffolds of $50.3 \mathrm{Mb}$ in length and 648 genes. There was no significant enrichment of Gene Ontology (GO) categories for genes within this region. There were 21 putative NLR, 18 TNL and three CNL, found in clusters representing one TNL and three different CNL families (Fig. 4; Table 2). Eighteen TNL were ascribed to the $R G C 12$ gene family, based on their NB sequences. Of the remaining NLR-encoding genes, three were ascribed to three CNL subfamilies (Table 3). The 18 members of the $R G C 12$ family were located within a segment of MRC4 consisting of 32 scaffolds that spanned $13 \mathrm{Mb}$, and 17 members of $R G C 12$ were found within $6.5 \mathrm{Mb}$. The few other NLR in MRC4 were more widely distributed across the region (Fig. 4).

Table 1. Gene ontology (GO) biological process terms significantly enriched among genes within the major resistance cluster on chromosome 1 (MRC1)

\begin{tabular}{|c|c|c|c|c|c|c|c|c|c|}
\hline \multirow[b]{2}{*}{ GO term } & \multirow[b]{2}{*}{ Genome wide } & \multicolumn{4}{|c|}{ Full MRC1 gene set ${ }^{a}$} & \multicolumn{4}{|c|}{ Excluding NLR-encoding genes ${ }^{c}$} \\
\hline & & Obs. & Exp. & Fold enr. & $P$ value ${ }^{b}$ & Obs. & Exp. & Fold enr. & $P$ value $^{\text {d }}$ \\
\hline Innate immune response & 199 & 51 & 4.4 & 11.6 & $<0.0001$ & 6 & 2.9 & 2.0 & ne \\
\hline Apoptosis & 343 & 66 & 7.6 & 8.7 & $<0.0001$ & 1 & 5.5 & 5.5 & ne \\
\hline Defense response & 384 & 62 & 8.5 & 7.3 & $<0.0001$ & 1 & 6.4 & 6.4 & ne \\
\hline Signal transduction & 361 & 51 & 7.9 & 6.4 & $<0.0001$ & 6 & 6.2 & 1.0 & ne \\
\hline Protein phosphorylation & 1447 & 59 & 31.8 & 1.9 & 0.0006 & 57 & 28.7 & 2.0 & 0.0002 \\
\hline
\end{tabular}

${ }^{a}$ Number of genes genome-wide, observed (Obs.), and expected (Exp.); enr. = enrichment.

b Adusted $P$ value for enrichment.

${ }^{c}$ NLR = nucleotide binding-leucine rich repeat. Number of genes observed and expected; enr. = enrichment.

d Adjusted $P$ value for enrichment; ne $=$ nonestimable, $>0.99$.

Table 2. Distribution of nucleotide binding-leucine rich repeat (NLR)-encoding gene models identified in the major resistance cluster on chromosomes 1 and 4 (MRC1 and MRC4) $)^{\mathrm{a}}$

\begin{tabular}{|c|c|c|c|c|c|c|c|c|}
\hline Genomic region & TIR-NB-LRR ${ }^{a}$ & TIR-NB & $\mathrm{NB}_{\text {TIR-LRR }}$ & $\mathrm{NB}_{\mathrm{CC}}-\mathrm{LRR}$ & $\mathrm{NB}_{\mathbf{C C}}$ & TIR & $\mathrm{NB}_{\text {TIR }}$ & LRR \\
\hline MRC1 & 55 & 6 & 0 & 17 & 3 & 8 & 3 & 10 \\
\hline MRC4 & 14 & 1 & 1 & 2 & 1 & 2 & 2 & 13 \\
\hline
\end{tabular}

a Number of characteristic domains present in each gene model. Domains described in subscripts refer to the type of nucleotide binding (NB) domain by homology to known TNL (N-terminal domains with toll interleukin receptors [TIR]) or CNL (coiled-coil terminal domains); LRR = leucine-rich repeat. 
Table 3. Family assignment of the nucleotide binding-leucine rich repeat (NLR)-encoding genes in the major resistance clusters on chromosomes 1 and $4\left(\mathrm{MRC} 1\right.$ and MRC4) ${ }^{\mathrm{a}}$

\begin{tabular}{lccc}
\hline NLR family & NLR subtype & MRC1 & MRC4 \\
\hline$R G C 1$ & CNL & 17 & 0 \\
$R G C 2$ & CNL & 0 & 1 \\
$R G C 6$ & CNL & 1 & 0 \\
$R G C 31$ & CNL & 2 & 0 \\
$R G C 26$ & CNL & 0 & 1 \\
$R G C 32$ & CNL & 0 & 1 \\
$R G C 14$ & TNL & 1 & 0 \\
$R G C 12$ & TNL & 0 & 18 \\
$R G C 16$ & TNL & 62 & 0 \\
Not assigned & & 1 & 0 \\
Total & & 84 & 21 \\
\hline
\end{tabular}

${ }^{\text {a }}$ Based on the phylogenetic analysis of 385 putative NLR in the reference cv. Salinas genome (unpublished).
NLR content within the MRC4 region was largely conserved across four lettuce genotypes. The genome assemblies for L. sativa cvs. Diana and Valmaine and the L. serriola accession US96UC23 (data unpublished) were mined for the NLRencoding genes found in MRC4 as described for MRC1. Similar sequences were identified for all 21 NLR in at least one of the three genotypes (Supplementary Table S4). Most of the genes were conserved, with higher sequence identity among genotypes of $L$. sativa. Cultivars Diana and Valmaine had an average sequence identity of 99 and $98 \%$ for 20 and 18 NLR in MRC4, respectively, compared with cv. Salinas. As expected, NLR genes from $L$. serriola shared lower sequence identity with cv. Salinas with an average of $97.1 \%$ identity for 14 of 21 NLR. Four pairs of NLR paralogs located within $30 \mathrm{~kb}$ of one another were found on the same scaffold in one or more of these assemblies at a physical distance almost identical to the

Table 4. Sequences within major resistance clusters on chromosomes 1 and 4 (MRC1 and MRC4) targeted for RNAi in stable transgenics, resistance specificities tested, Bremia lactucae isolates, and phenotypic outcome ${ }^{\mathrm{a}}$

\begin{tabular}{|c|c|c|c|c|c|c|}
\hline RNAi construct & 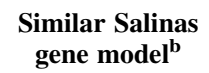 & $\begin{array}{l}\text { Germplasm } \\
\text { background }^{c}\end{array}$ & Specificities $^{d}$ & Isolates $^{\mathbf{e}}$ & Effectors ${ }^{f}$ & Silenced genes ${ }^{g}$ \\
\hline \multicolumn{7}{|l|}{ MRC1 } \\
\hline \multirow[t]{4}{*}{ QGF20G21_LRR_RNAi } & $\begin{array}{l}\text { Lsa025432.1 } \\
\quad(96 \%), R G C 1\end{array}$ & Diana & $\begin{array}{l}D m 1, D m 3, D m 5 / 8, \\
\quad D m 7\end{array}$ & $\begin{array}{l}\text { C83M47 (Avr1), Am } \\
\text { (Avr3), CG1 (Avr5/8), } \\
\text { R60 (Avr7) }\end{array}$ & None & $d m 5 / 8$ \\
\hline & & Ninja & $D m 36$ & CG1 (Avr36) & $\begin{array}{l}\text { AvrB, } \\
\text { Avrpm1, } \\
\text { AvrRpt2 }\end{array}$ & None \\
\hline & & Diana $\times$ Valmaine & $D m 5 / 8$ & CG1 (Avr5/8) & None & $d m 5 / 8$ \\
\hline & & Diana $\times$ UCDm10 & Dm10 & SF3 (Avr10) & None & \\
\hline \multirow[t]{6}{*}{ QGF16M04_LRR_RNAi } & $\begin{array}{l}\text { Lsa039421.1 } \\
(88 \%),\end{array}$ & $\begin{array}{l}\text { Valmaine } \times \text { Cobham } \\
\text { Green }\end{array}$ & $D m 5 / 8$ & CG1 (Avr5/8) & None & $d m 5 / 8$ \\
\hline & $R G C 1$ & $\begin{array}{l}\text { UCDm10 } \times \text { Cobham } \\
\text { Green }\end{array}$ & Dm10 & C83M47 (Avr10) & None & None \\
\hline & & Ninja & $\begin{array}{l}\text { Dm36, HR to AvrB, } \\
\text { AvrRpm1, AvrRpt2 }\end{array}$ & CG1 (Avr36) & $\begin{array}{l}\text { AvrB, } \\
\text { Avrpm1, } \\
\text { AvrRpt2 }\end{array}$ & $\begin{array}{l}H R-A v r B \\
H R-A v r R p m 1, \\
H R-A v r R p t 2\end{array}$ \\
\hline & & $\begin{array}{l}\text { L. serriola acc LSE } 102 \times \\
\text { Cobham Green }\end{array}$ & Dm17 & C01O879 (Avr17) & None & None \\
\hline & & $\begin{array}{l}\text { L. serriola accession } \\
\text { CGN14263 × Cobham } \\
\text { Green }\end{array}$ & $D m 43$ & C01O879 (Avr43) & None & None \\
\hline & & $\begin{array}{l}\text { 09G952 × Cobham } \\
\text { Green }\end{array}$ & $D m 45$ & C01O879 (Avr45) & None & $d m 45$ \\
\hline \multicolumn{7}{|l|}{ MRC4 } \\
\hline \multirow[t]{5}{*}{ CLSX586_NB_RNAi } & $\begin{array}{l}\text { Lsa007832.3 } \\
(99.9 \%)\end{array}$ & $\begin{array}{l}\text { R4T57 × Cobham } \\
\text { Green }\end{array}$ & Dm4 & C980648ED (Avr4) & None & $d m 4$ \\
\hline & $R G C 12$ & $\begin{array}{l}\text { LSE57/15 × Cobham } \\
\text { Green }\end{array}$ & $D m 7$ & R60 (Avr7) & None & $d m 7$ \\
\hline & & Diana $\times$ Cobham Green & $D m 3, D m 5 / 8, D m 7$ & $\begin{array}{r}\text { IM25P11 (Avr3), CG1 } \\
(\text { Avr5/8), R60 (Avr7) }\end{array}$ & None & $d m 7$ \\
\hline & & $\begin{array}{l}\text { Capitan } \times \text { Cobham } \\
\text { Green }\end{array}$ & Dm11 & CG1 (Avr11) & None & $d m 11$ \\
\hline & & $\begin{array}{l}\text { L. serriola accession } \\
\text { CGN14263 } \times \text { Cobham } \\
\text { Green }\end{array}$ & $D m 44$ & C01O879 (Avr44) & None & $d m 44$ \\
\hline \multirow[t]{4}{*}{ CLSS6596_TIR_RNAi } & $\begin{array}{l}\text { Lsa011787.1 } \\
\quad(94.6 \%)\end{array}$ & $\begin{array}{l}\text { R4T57 × Cobham } \\
\text { Green }\end{array}$ & Dm4 & C980648ED (Avr4) & None & $d m 4$ \\
\hline & $R G C 12$ & $\begin{array}{l}\text { LSE57/15 × Cobham } \\
\text { Green }\end{array}$ & $D m 7$ & R60 (Avr7) & None & None \\
\hline & & $\begin{array}{l}\text { Capitan } \times \text { Cobham } \\
\text { Green }\end{array}$ & Dm11 & CG1 (Avr11) & None & $d m 11$ \\
\hline & & $\begin{array}{l}\text { L. serriola accession } \\
\text { CGN14263 × Cobham } \\
\text { Green }\end{array}$ & $D m 44$ & C01O879 (Avr44) & None & $d m 44$ \\
\hline
\end{tabular}

\footnotetext{
a Only constructs resulting in an abrogated resistance phenotype are included.

b Percent identity shown in parentheses, followed by the name of the nucleotide binding-leucine rich repeat (NLR) family.

c Genetic background of RNAi transgenics.

${ }^{\mathrm{d}}$ Dm or HR specificities tested. Genes expressed in wild-type genotypes and evaluated for abrogration by RNAi in stable transgenics.

e Isolates tested, followed by the relevant avirulence (Avr) effectors in parentheses.

${ }^{\mathrm{f}}$ Effectors tested by agroinfiltration with $\mathrm{C} 58 \mathrm{C} 1$ strains expressing bacterial effectors.

${ }^{\mathrm{g}}$ Genes which were abrogated by the silencing construct.
} 
distance in cv. Salinas, suggesting the order of genes is conserved among these genotypes.

The RGC12 family contains candidates for Dm7. In previous mapping studies, the EST CLSX586 represented the only candidate gene that completely cosegregated with $\mathrm{Dm} 7$ (McHale et al. 2009), making the NLR gene encoding this partial cDNA

Table 5. Lettuce genotypes and their respective resistance specificities that were used as sources of disease resistance or hypersensitive response (HR) for RNAi experiments

\begin{tabular}{llc}
\hline $\begin{array}{l}\text { Lettuce cultivars or } \\
\text { breeding lines }\end{array}$ & \multicolumn{1}{c}{$\begin{array}{c}\text { Resistance } \\
\text { specificity }\end{array}$} & $\begin{array}{c}\text { HR to bacterial } \\
\text { effectors }^{\mathbf{a}}\end{array}$ \\
\hline Capitan & Dm11 & NET \\
CGN14263 & Dm43, Dm44 & NET \\
LSE57/15 & Dm7 & NET \\
R4T57 & $D m 4$ & NET \\
Diana & $D m 1, D m 3, D m 5 / 8$, & NET \\
& $D m 7$ & \\
Ninja & Dm3, Dm11, Dm36 & AvrB, AvrRpm1, \\
& & AvrRpt2 \\
Valmaine & Dm5/8, Tu, Fus1 & AvrPpiC, AvrRps4 \\
UCDM10 & $D m 10$ & NET \\
LSE102 & $D m 17$ & NET \\
09G1126 & $D m 43$ & NET \\
09G952 & $D m 45$ & NET \\
Cobham Green & None known & NET \\
\hline
\end{tabular}

a NET $=$ no effectors tested for HR. and its closely related paralogs obvious targets for further analysis. The full-length gene was amplified and sequenced from genomic DNA of cv. Diana. Phylogenetic clustering showed that this gene belongs to the RGC12 family that codes a TNL, and the gene was subsequently named $R G C 12 G$ (McHale et al. 2009). Analysis of the coding sequence using Pfam (Finn et al. 2006) identified TIR, NB-ARC, and eleven putative LRR domains (Fig. 5). Southern analysis revealed that $R G C 12 G$ belongs to a multigene family located on at least nine different genomic fragments (Supplementary Fig. S2). Phylogenetic analysis of 385 NLR-encoding genes in cv. Salinas revealed that the $R G C 12$ family consists of 53 genes in cv. Salinas, but only 15 are located within MRC4.

RNAi elicits the loss of multiple downy mildew resistance specificities within MCR4. RNAi was used to evaluate whether candidate NLR-encoding genes in MRC4 determined the four colocalized DM resistance specificities ( $\mathrm{Dm} 4, \mathrm{Dm} 7, \mathrm{Dm} 11$, and Dm44). The silencing constructs were transformed into the susceptible cv. Cobham Green. Primary transgenics exhibiting strong silencing of GUS were crossed to four different genotypes carrying each of the DM resistance specificities (Fig. 2; Table 4).

All 10 of the $\mathrm{T}_{1}$ plants generated with the CLSX586_LRR_RNAi construct, which targeted the LRR region of $R G C 12 G$, showed robust GUS expression in the Agrobacterium-mediated transient assays. This lack of silencing for the reporter gene implied that the target gene would also not have been silenced, and

\section{A GUS expression on $\mathrm{T}_{1}$}
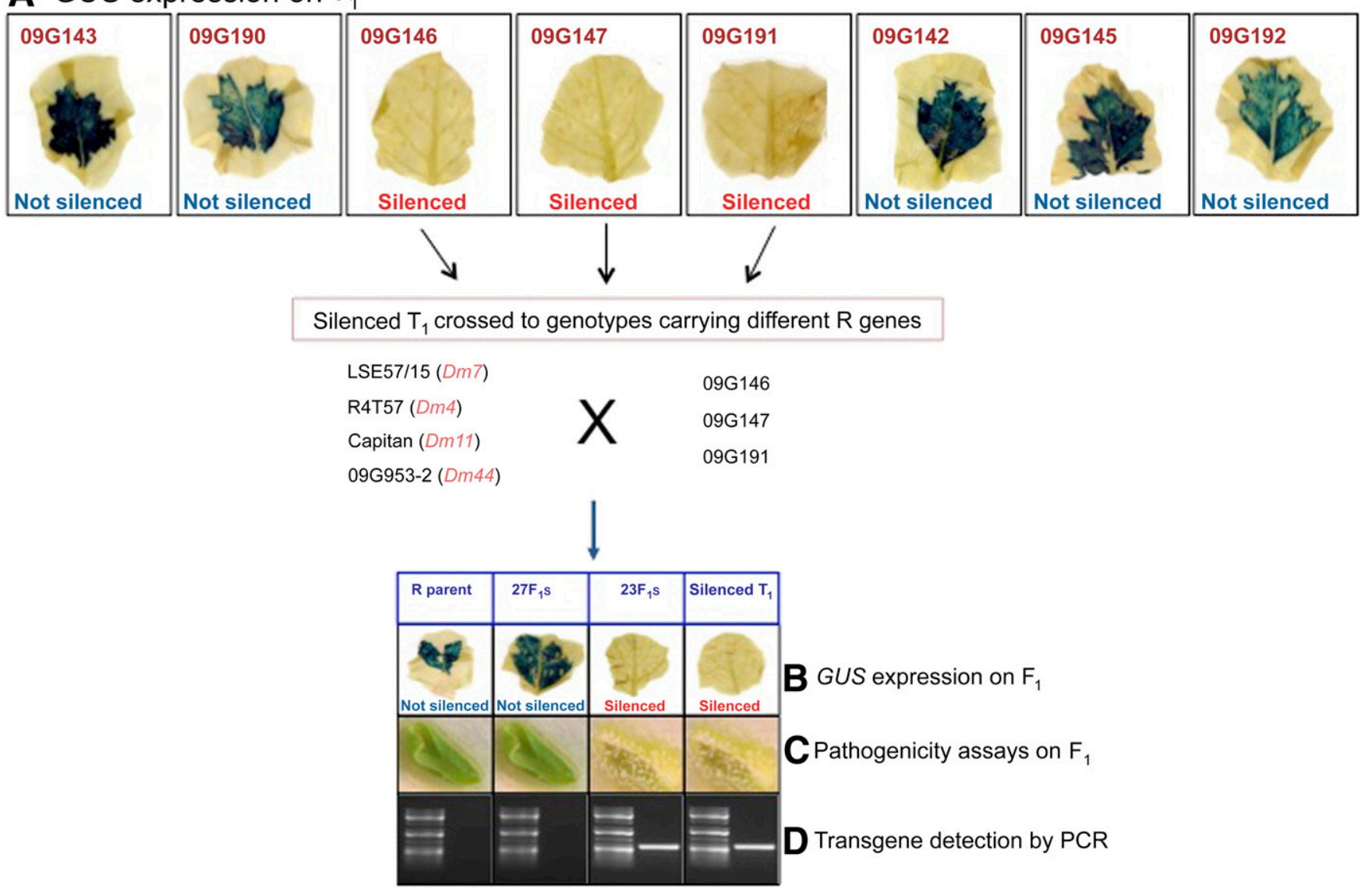

Fig. 2. Experimental design for the functional analysis of $R G C 12 G$. This particular scheme shows the strategy applied for the CLSX586_NB_RNAi construct but the methodology applies to all constructs (different genetic backgrounds and diagnostic isolates in each case). A, Agrobacterium tumefaciens-mediated transient assays were used to determine RNAi efficiency. $\mathrm{T}_{1}$ plants showing lack of $\beta$-glucuronidase $(G U S)$ expression were selected for pathogenicity assays. Cross pollination was carried out to introduce the transgene to the appropriate genetic background. B, $\mathrm{F}_{1}$ plants were evaluated for RNAi efficiency based on GUS expression levels. C, Pathogenicity assays were performed at the cotyledon and three- to four-leaf stage. D, Sporulation was recorded only in the presence of the RNAi construct as demonstrated by polymerase chain reaction detection (PCR) and by transient GUS expression assays (not shown). 
therefore, this construct was not evaluated for suppression of disease resistance. The average rate of successful silencing using this vector in lettuce is approximately $20 \%$. However, with some constructs, this frequency is considerably lower.
While lack of RNAi could be related to this particular construct, LRR fragments have been used successfully for silencing other gene targets (e.g., QGF20G21 and QGF16M04). An alternative, a construct targeting the NB-encoding region of $R G C 12 G$,

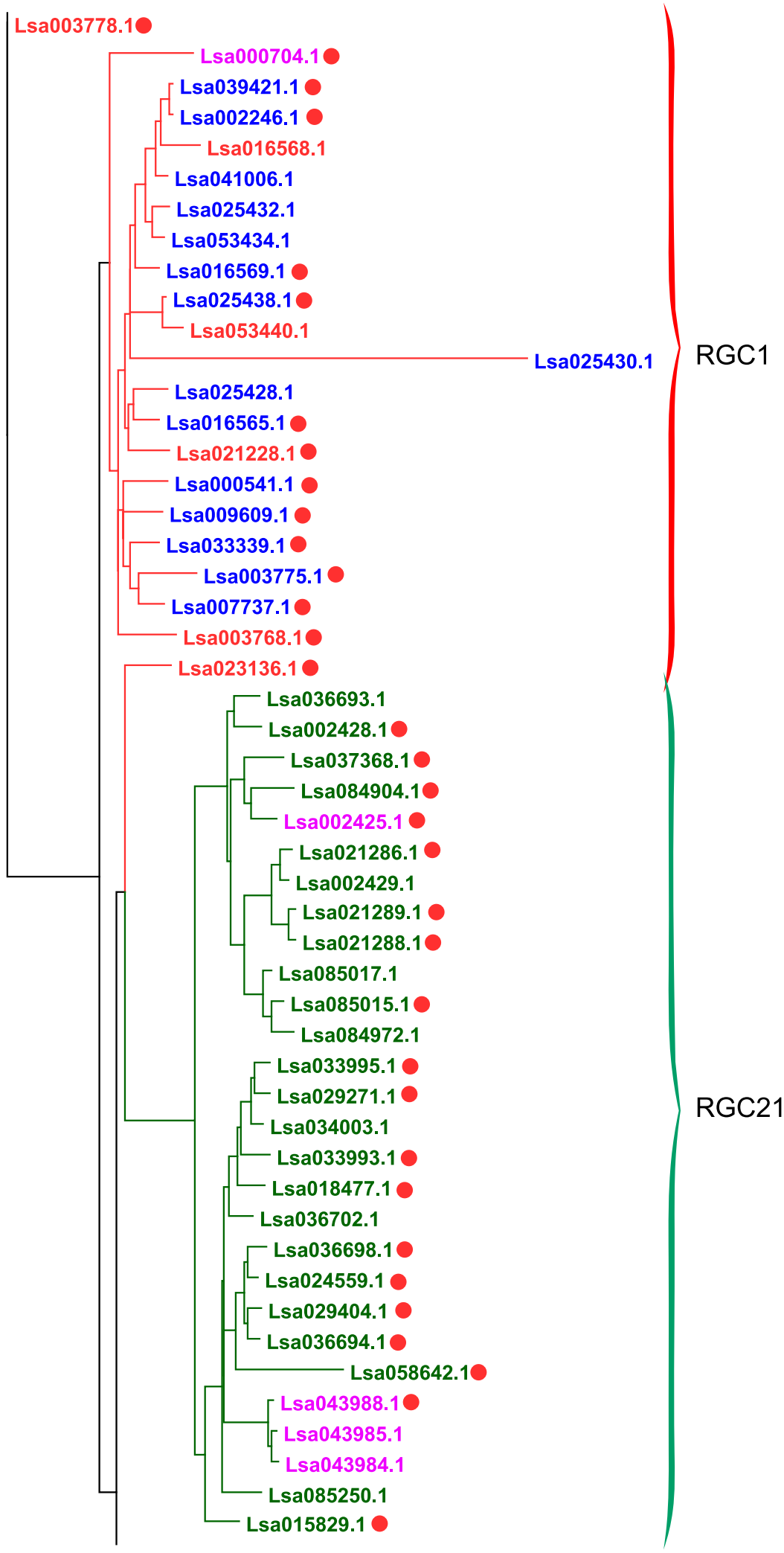

Fig. 3. Members of $R G C 1$ (in red) and $R G C 21$ (in green) families. Genes colored in blue are predicted to be targeted by both QGF16M04_LRR_RNAi and QGF20G21_LRR_RNAi and genes colored in purple only by QGF20G21_LRR_RNAi. The RGC21 genes targeted for RNAi map to a different chromosome. Red dots indicate evidence of transcription in cv. Salinas. 
was generated. This CLSX586_NB_RNAi construct elicited the loss of $D m 7$ specificity in $\mathrm{F}_{1}$ plants of LSE57/15 $\times$ siCobham Green-CLSX586_NB as well as Dm4, Dm11, and Dm44 resistance specificities in other crosses (Table 4). Perfect cosegregation of the transgene, the lack of GUS transient expression, and loss of resistance occurred in all three independent transgenic lines (Fig. 2). $\mathrm{F}_{1}$ plants with cv. Diana
(Dm3, Dm7, Dm5/8) were also tested for resistance conferred by the unlinked resistance genes $D m 3$ and $D m 5 / 8$. These resistance specificities were not compromised, showing that the RNAi was specific to the Dm genes within MRC4 rather than a nonspecific suppression of $D m$ activity.

The CLSS6596_TIR_RNAi construct targeting the TIR region encoded by CLSS6596 abrogated $\mathrm{Dm} 4, \mathrm{Dm} 11$, and $\mathrm{Dm} 44$,

Table 6. Comparison of all RGC1 members of the major resistance clusters on chromosome 1 (MRC1) in cvs Salinas, Diana, and Valmaine and their identification as silencing targets for the two RNAi constructs that abrogated $D m 5 / 8^{\mathrm{a}}$

\begin{tabular}{|c|c|c|c|c|c|c|c|c|c|c|c|c|}
\hline \multirow[b]{2}{*}{ Distance $^{b}$} & \multirow[b]{2}{*}{ Genes } & \multicolumn{2}{|c|}{ Construct $^{c}$} & \multirow[b]{2}{*}{ Best hit ${ }^{\mathrm{d}}$} & \multirow[b]{2}{*}{ Identity } & \multicolumn{2}{|c|}{ Construct $^{\mathrm{c}}$} & \multirow[b]{2}{*}{ Best hit ${ }^{\mathrm{e}}$} & \multirow[b]{2}{*}{ Identity } & \multicolumn{2}{|c|}{ Construct $^{\mathbf{c}}$} & \multirow[b]{2}{*}{ Expressed } \\
\hline & & 1 & 2 & & & 1 & 2 & & & 1 & 2 & \\
\hline 0 & Lsa007737.1 & $\mathrm{T}$ & $\mathrm{T}$ & 3266 & $100.00 \%$ & $\mathrm{~T}$ & $\mathrm{~T}$ & $\mathrm{Nd}^{\mathrm{c}}$ & & & & Yes \\
\hline 584,285 & Lsa009609.1 & $\mathrm{T}$ & $\mathrm{T}$ & 3792 & $100.00 \%$ & $\mathrm{~T}$ & $\mathrm{~T}$ & 13227 & $99.60 \%$ & $\mathrm{~T}$ & & Yes \\
\hline $2,666,193$ & Lsa000704.1 & & $\mathrm{T}$ & 3314 & $100.00 \%$ & & $\mathrm{~T}$ & 35281 & $100.00 \%$ & & $\mathrm{~T}$ & Yes \\
\hline $3,281,947$ & Lsa003778.1 & & & 23462 & $100.00 \%$ & & & 39944 & $96.80 \%$ & & & Yes \\
\hline 165,356 & Lsa003768.1 & & & 3361 & $100.00 \%$ & & & 2878 & $97.70 \%$ & & & \\
\hline 19,009 & Lsa003775.1 & $\mathrm{T}$ & $\mathrm{T}$ & 3361 & $100.00 \%$ & $\mathrm{~T}$ & $\mathrm{~T}$ & 2878 & $99.90 \%$ & $\mathrm{~T}$ & $\mathrm{~T}$ & Yes \\
\hline $15,458,010$ & Lsa021227.1 & $\mathrm{T}$ & $\mathrm{T}$ & 138 & $100.0 \%$ & $\mathrm{~T}$ & $\mathrm{~T}$ & 37211 & $96.0 \%$ & $\mathrm{~T}$ & $\mathrm{~T}$ & Yes \\
\hline 9 & Lsa021228.1 & & & 138 & $100.00 \%$ & & & 37211 & $96.80 \%$ & & & Yes \\
\hline $1,786,030$ & Lsa025428.1 & $\mathrm{T}$ & $\mathrm{T}$ & 8422 & $100.00 \%$ & & & $\mathrm{Nd}$ & & & & \\
\hline 61,386 & Lsa025430.1 & $\mathrm{T}$ & $\mathrm{T}$ & 10889 & $100.00 \%$ & $\mathrm{~T}$ & $\mathrm{~T}$ & $\mathrm{Nd}$ & & & & \\
\hline 158,793 & Lsa025438.1 & $\mathrm{T}$ & $\mathrm{T}$ & 16325 & $99.90 \%$ & $\mathrm{~T}$ & $\mathrm{~T}$ & 9593 & $92.40 \%$ & $\mathrm{~T}$ & $\mathrm{~T}$ & Yes \\
\hline 2,434 & Lsa053434.1 & $\mathrm{T}$ & $\mathrm{T}$ & 34679 & $99.80 \%$ & $\mathrm{~T}$ & & $\mathrm{Nd}$ & & & & \\
\hline 32,932 & Lsa025433.1 & & & 11564 & $100.0 \%$ & & & 57340 & $99.0 \%$ & & & \\
\hline 27,969 & Lsa025432.1 & $\mathrm{T}$ & $\mathrm{T}$ & 11564 & $99.90 \%$ & $\mathrm{~T}$ & $\mathrm{~T}$ & $\mathrm{Nd}$ & & $\mathrm{T}$ & $\mathrm{T}$ & \\
\hline $2,391,866$ & Lsa039421.1 & $\mathrm{T}$ & $\mathrm{T}$ & 10227 & $99.90 \%$ & $\mathrm{~T}$ & $\mathrm{~T}$ & $\mathrm{Nd}$ & & & & Yes \\
\hline 24,378 & Lsa039417.1 & $\mathrm{T}$ & $\mathrm{T}$ & 10227 & $100.0 \%$ & & & 16352 & $88.9 \%$ & $\mathrm{~T}$ & & \\
\hline $4,781,178$ & Lsa002246.1 & $\mathrm{T}$ & $\mathrm{T}$ & 32578 & $95.30 \%$ & $\mathrm{~T}$ & $\mathrm{~T}$ & $\mathrm{Nd}$ & & & & Yes \\
\hline
\end{tabular}

a Only Lsa003775.1, Lsa025438.1, and Lsa021227.1 are potential RNAi targets in all genotypes by both constructs and are transcribed.

b Distance (measured in kilobases) from previous gene in Lactuca sativa cv. Salinas.

c Construct 1 is QGF16M04_LRR_RNAi and construct 2 is QGF20G21_LRR_RNAi. T = targeted for RNAi.

${ }^{\mathrm{d}}$ Scaffold with best Blast hit in L. sativa cv. Diana.

e Scaffold with best BLAST hit in L. sativa cv. Valmaine. Nd - not detected.

${ }^{\mathrm{f}}$ Evidence of expression in L. sativa cv. Salinas.

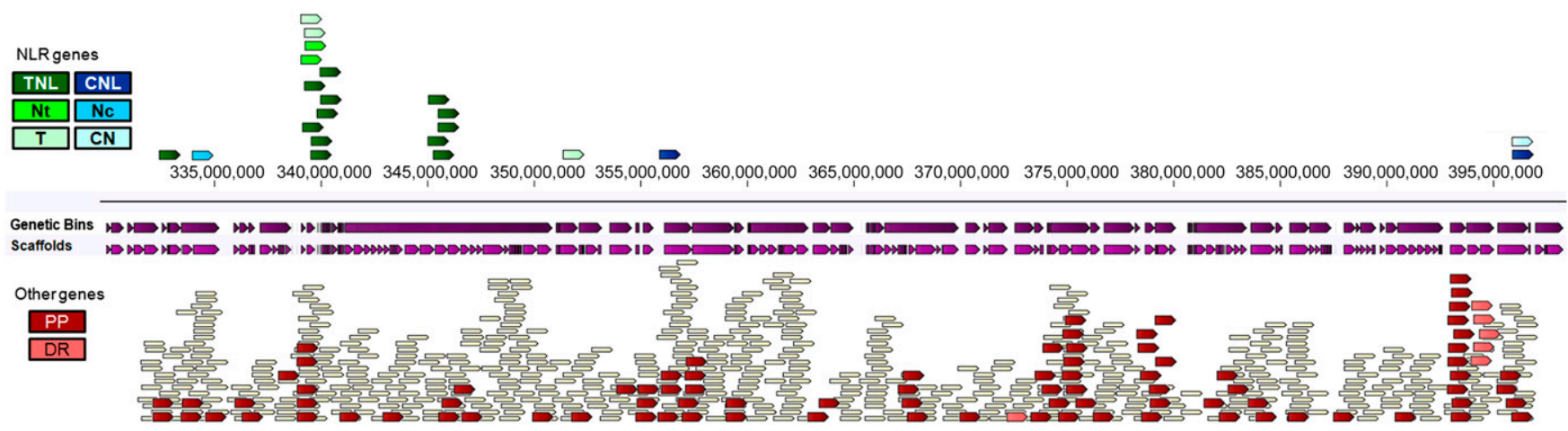

Fig. 4. Graphical overview of the major resistance cluster on chromosome 4 (MRC4). The top panel shows NLR (nucleo binding-leucine rich repeat [NB-LRR]) genes mapped relative to the scaffolds and the genetic bins of the reference genome assembly of Lactuca sativa cv. Salinas (Lsat.1.v6.lg), whereas the bottom panel shows all other genes that map to this locus. The genes are color-coded: TNL (N-terminal domains with toll interleukin receptors [TIR]) are shown in shades of green and CNL (coiled-coil [CC] terminal domains) in shades of blue, other genes involved in defense response (DR) genes are in pink, protein phosphorylation (PP) in red, and the remainder of the genes in yellow. The NLR are subdivided into different groups based on the number of domains detected. N = NB, L = LRR, $\mathrm{C}=\mathrm{CC}, \mathrm{T}=\mathrm{TIR}$. Lower case letters are used when the domain itself is not present but inferred based on the phylogeny of the NB domain.

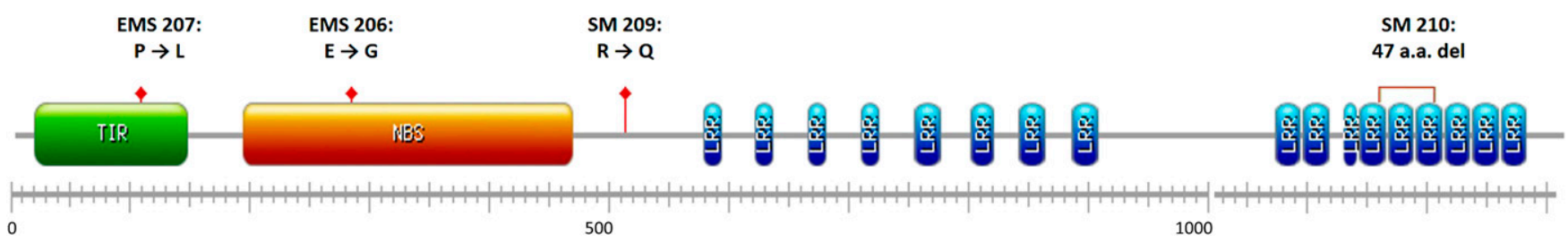

Fig. 5. Protein domains of the coding region of $R G C 12 G$ are shown. Red markers indicate mutation sites. Protein domains were predicted with Pfam. Figure was drawn with ExPASy (Gasteiger et al. 2003). 
but not $D m 7$ (Table 4). Loss of resistance was confirmed only for the $\mathrm{F}_{1}$ plants that carried the transgene, all of which showed inhibition of GUS expression. Silencing of GUS occurred and segregated in $F_{1}$ plants, indicating sufficient silencing of the genes within the construct. However, regardless of presence or absence of the transgene, all the $\mathrm{F}_{1}$ plants derived from crosses with cv. Diana retained the $D m 7$ resistance phenotype.

The CLSM18700_LRR_RNAi construct targeting the LRR domain encoded by the CLSM18700 did not confer loss of resistance. The $\mathrm{F}_{1}$ plants segregated in a 1:1 ratio for the RNAi construct as verified by PCR and Agrobacterium tumefaciensmediated inhibition of GUS expression (Fig. 2). Therefore, there is no evidence that CLSM18700 is required for Dm4-, Dm7-, Dm11-, or Dm44-mediated resistance.

BLAST searches against the reference genome of cv. Salinas identified Lsa025738.1 (99.4\% identity) and Lsa011787.1 (94.6\% identity) as the full-length genes for CLSM18700 and CLSS6596, respectively. Phylogenetic analysis of the NB domains of the three genes targeted for RNAi (Supplementary Fig. S3) revealed that all of them are members of the $R G C 12$ family (McHale et al. 2009). The membership of CLSS6596 in the $R G C 12$ family is consistent with $D m 4, D m 11$, and $D m 44$ being compromised by this RNAi construct. However, the nucleotide sequences of CLSS6596 and $R G C 12 G$ are very diverse; no stretches of 21 nucleotides (nt) or longer are identical between their two TIR domains. This is consistent with the idea that $D m 7$ resistance phenotype being unaffected by trigger sequences derived from CLSS6596 (Supplementary Fig. S4).

RNAi constructs target specific families of NLR-encoding genes in MCR4 for silencing. The genome of cv. Salinas was searched for the presence of stretches of $21 \mathrm{nt}$ with a $100 \%$ identity to the RNAi trigger sequence to identify genes targeted for silencing. Only NLR-encoding genes were identified as potential targets. With few exceptions, each construct targeted members of a specific family of NLR-encoding genes (Fig. 6). CLSM18700_LRR_RNAi, CLSS6596_TIR_RNAi, and CLSX586_NB_RNAi targeted members of the RGC12 family (Table 7). Of the 12 NLR-encoding genes within MRC4 in cv. Salinas that are targeted by both CLSS6596_TIR_RNAi and CLSX586_NB_RNAi, only five are not targeted by CLM18700_LRR_RNAi (Table 7; Fig. 6). Therefore, one or more of these five NLR-encoding genes were the best candidates for $D m 7, D m 4, D m 11$, and $D m 44$.

Sequence analysis of $\mathrm{dm} 7$ loss-of-resistance mutant lines identifies a causal gene. Previous studies had identified loss-ofresistance mutants from fast neutron and ethyl methanesulfonate (EMS) mutagenized populations of cv. Diana as well as one spontaneous mutant (Chin et al. 2001). RGC12G, which cosegregated with $D m 7$ (McHale et al. 2009), was specifically amplified and sequenced from six $d m 7$ loss-of-resistance mutant lines derived from cv. Diana. In-frame mutations relative to the wild-type sequence were identified in four of these mutant lines. Spontaneous mutant 210 had an in-frame 141-bp deletion flanked by $30 \mathrm{nt}$ repeated on either side of the deletion (Fig. 5). Spontaneous mutant 209, EMS mutant 206, and EMS mutant 207 had single nucleotide changes resulting in an Arg to Gln change in the linker region between the NB and LRR domains, a Gly to Glu change in the NB domain, and a Pro to Leu change in the TIR domain, respectively (Fig. 5). No DNA lesions were found in the sequence of $R G C 12 G$ from the two remaining mutant lines. Lesions may be present in an unsequenced upstream regulatory region. Prior allelism tests for the six recessive $D m 7$ mutants had shown no evidence for intergenic complementation indicating that mutations were all in the same required gene (Chin et. al. 2001; Okubara et al. 1994). The hybridization patterns from Southern blotting revealed no detectable copy number variation between the wild type and the mutant accessions (Fig. 5). These sequence changes in the four independent mutant lines provide strong evidence that $\mathrm{Dm} 7$ resistance specificity is conferred by $R G C 12 G$.

\section{DISCUSSION}

\section{NLR-encoding genes within MRC1 and MRC4} are distributed among nonresistance-related genes.

The genomic architecture of lettuce at MRC1 and MRC4 is consistent with genes conferring disease resistance being clustered in the genome in lettuce and plants in general (Meyers et al. 1998; Michelmore and Meyers 1998). The genome sequence reveals the genetic complexity of these loci with three different gene families located in local clusters surrounded by nonresistance-related genes (Table 3; Figs. 1 and 4). Similar to MRC2, which predominantly consists of members of the CNL-encoding $R G C 2$ family (Kuang et al. 2004; Shen et al. 2002), members of the RGC16 (TNL) and RGCl (CNL) families predominate at MRC1 and members of the $R G C 12$ (TNL) family predominate at MRC4, although a few representatives of other subfamilies are present in both regions (Table 3). Both regions are enriched for TNL rather than CNL.

\section{The $R G C 12$ family of TNL encodes multiple resistance specificities at MRC4.}

RNAi elicited loss of all or a subset of the downy mildew resistance specificities within MRC4 (Dm4, Dm7, Dm11, $D m 44)$ by two different $R G C 12$ family members ( $R G C 12 G$ and $C L S S 6596$ ), indicating that one or more $R G C 12$ family members are required for all of the known DM resistance specificities at this locus. Constructs, such as CLSX586_NB_RNAi used in silencing $R G C 12 G$, which target the conserved region around the MHD motif in the NB domain would be expected to silence multiple closely related genes (Fig. 6). The simultaneous silencing of $\mathrm{Dm} 7, \mathrm{Dm} 4, \mathrm{Dm} 1 \mathrm{l}$, and $\mathrm{Dm} 44$ and the physical clustering of $R G C 12$ family members is consistent with the lack of recombinants observed between $D m 4, D m 7$, and Dm11 (Crute 1992). Three members of the RGC12 family were used for functional analyses using RNAi. The CLSM18700_RNAi targeting the LRR domain of RGC12E did not abrogate resistance. In contrast to the conserved NB domain of NLR, the LRR domain is highly diverse, with solventexposed residues exhibiting evidence of positive selection (McHale et al. 2006; Mondragón-Palomino et al. 2002). Thus, although the NB domains of $R G C 12 E$ and $R G C 12 G$ have high sequence similarity, the region of the LRR targeted by CLSM18700_LRR_RNAi is diverse (Supplementary Fig. S5) and is likely to silence a different subset of $R G C 12$ genes than the trigger sequences derived from $R G C 12 G$ and CLSS6596 (Table 7). Thus, a candidate gene list for $D m 4, D m 11$, and Dm44 resistance specificities has been generated that provides for future studies at the individual gene level (Table 7).

Spontaneous, fast neutron, and EMS-induced $d m 7$ loss-ofresistance mutants allowed us to identify a gene conferring $D m 7$. In-frame mutations in $R G C 12 G$ were observed in four of the six loss-of-resistance mutants, identifying $R G C 12 G$ as a gene conferring $D m 7$-mediated resistance to $B$. lactucae isolates carrying $A v r 7$ and highlighting the power of combining forward and reverse genetics. $R G C 12 G$ encodes a TNL protein with $41 \%$ similarity to $\mathrm{N}$ of Nicotiana tabacum, which mediates resistance to Tobacco mosaic virus (Whitham et al. 1994). This is the first report of a TNL conferring resistance in lettuce. The previously studied $D m$ genes at MRC2 are conferred by the CNL-encoding $R G C 2$ family (Shen et al. 2002; Wroblewski et al. 2007), although TNL have been identified as $R$ genes in 
numerous plant pathosystems (Borhan et al. 2008; Jebanathirajah et al. 2002; Yue et al. 2012), including resistance to downy mildew in Arabidopsis (Botella et al. 1998; Van Der Biezen et al. 2002).

\section{No functions were detected}

for the most prevalent NLR family within MRC1.

Within MRC2 and MRC4, the NLR family that was overrepresented controlled the majority of the resistance phenotypes

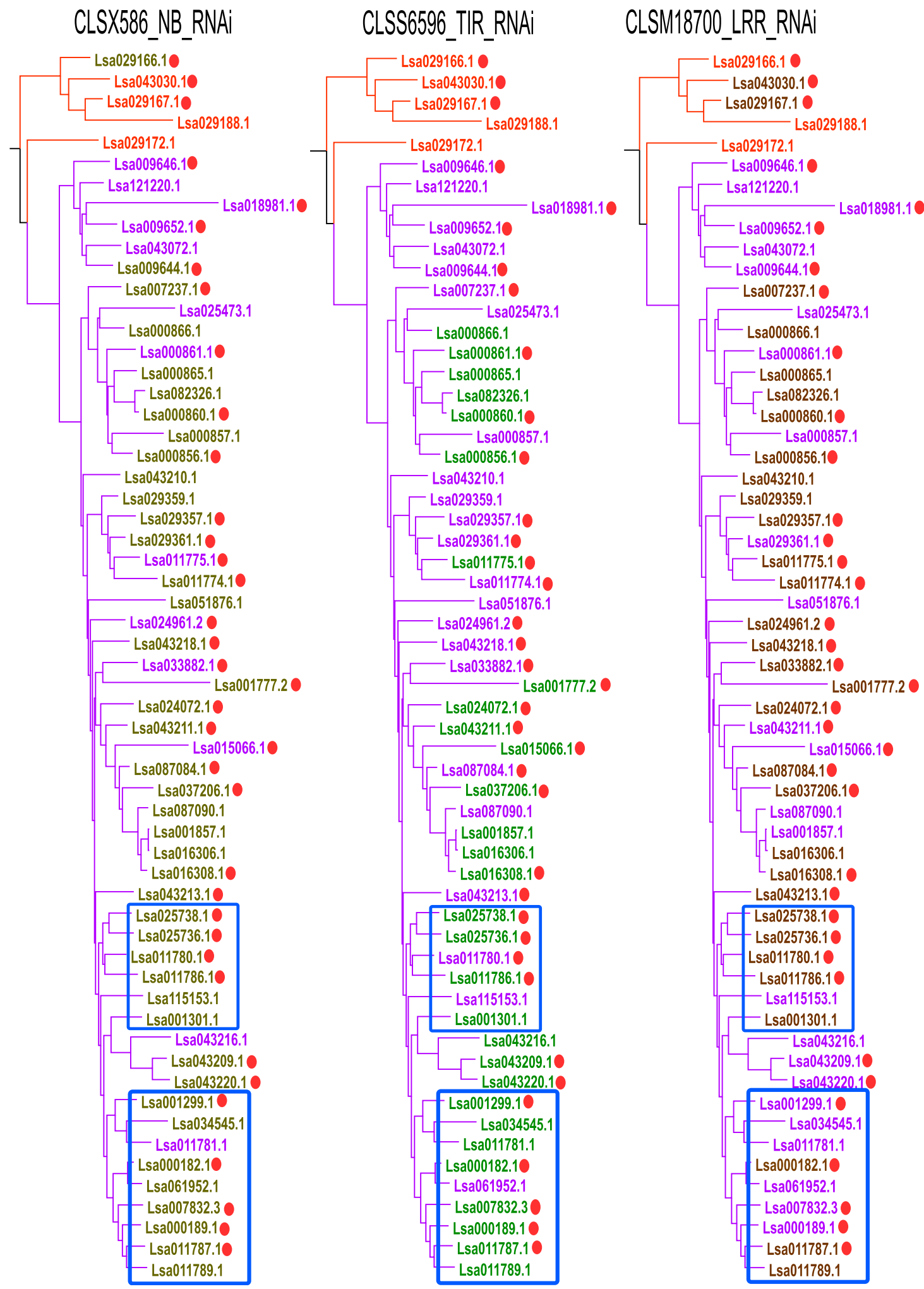

Fig. 6. The $R G C 12$ family members (in purple) targeted by each of the three constructs tested for MRC4-related phenotypes. $R G C 12$ genes are in purple, and $R G C 20$ members not targeted for RNAi are in orange. Khaki designates potential RNAi targets for CLSX586_NB_RNAi, green for CLSS6596_TIR_RNAi, and brown for CLSM18700_LRR_RNAi. Red dots indicate transcription. The blue boxes surround RGC12 members that map to MRC4. CLSM18700_LRR_RNAi did not abrogate any of the specificities of MRC4. CLSX586_NB_RNAi abrogated Dm4, Dm7, Dm11, and Dm44 and CLSS6596_TIR_RNAi abrogated Dm4, Dm11, Dm44, but not $D m 7$. 
mapping to the MRC. In contrast, silencing of six members of the $R G C 16$ family, which is the most prevalent NLR-encoding family in MRC1, did not result in abrogation of any of the nine tested DM resistance or HR phenotypes, even though six RNAi constructs were tested that targeted the majority of the RGC16 members (Supplementary Fig. S6). A few additional resistance phenotypes map to this region ( $p l r$ genes for resistance to Plasmopara lactucae-radicis and QTL for resistance to Fusarium and B. lactucae); these were not tested in this study and could be conferred by $R G C 16$ members. As new phenotypes are identified that map to MRC1, the RNAi tester stocks that we have generated will be utilized to evaluate the potential functions of these $R G C 16$ genes.

\section{Genes related to $Q G F 16 M 04$ are involved in both host and nonhost resistance.}

Silencing induced by the QGF16M04_LRR_RNAi construct demonstrated that the same or closely related genes encode resistance against the unrelated oomycete and bacterial pathogens, B. lactucae (Dm5/8 and Dm45) and Pseudomonas syringae (HR to bacterial effectors). This observation has several implications to the overall architecture of disease resistance in plants and the evolution of new resistance specificities. In Arabidopsis, the activities of effectors AvrB1, AvrRpm1, and AvrRpt2 that are secreted by P. syringae during infection are detected indirectly by two sequence-unrelated and genetically unlinked genes, RPM1 and RPS2, which encode CNL guarding the host protein RIN4. Phosphorylation of RIN4 within the AvrB binding site activates RPM1, whereas its cleavage within the AvrRpt2 cleavage site activates RPS2 (Axtell and Staskawicz 2003; Mackey et al. 2002, 2003). In soybean, detection of AvrB and AvrRpm1 is mediated by two sequence-related and tightly-linked CNL-encoding genes and has been reported to involve a RIN4 homolog (Ashfield et al. 2004; Chen et al. 2010). In lettuce, HR elicited by all three effectors genetically cosegregated to MRC1 and were silenced by the same RNAi construct. Because all three effectors are diverse, it is unlikely they activate one or more QGF16M04-homologous NLR through direct interaction, which would require three very different interaction surfaces among otherwise highly similar or the same proteins. However, multiple effectors can be detected by a single NLR (or a few close homologs) when one or more NLR guard a single common host target, such as RIN4. There are two RIN4 homologs in the lettuce genome; however, our attempts to individually or simultaneously silence these two homologs in cv. Ninja did not result in plants compromised for recognition of AvrB, AvrRpm1, or AvrRpt2, despite robust silencing of GUS (unpublished data). Incompatible combinations leading to hybrid dysgenesis involves LsRIN4 (chromosome 9) and a second locus located on chromosome 6 rather than MRC1 on chromosome 1 (Jeuken et al. 2009). These data suggest that LsRIN4 homologs may not be the targets of AvrB, AvrRpm1, or AvrRpt2 in lettuce. Numerous NOI-like proteins (Desveaux et al. 2007) are present in lettuce that share the AvrB binding and AvrRpt 2 cleavage sites with AtRIN4, making them potential targets of AvrB and AvrRpt2. QGF16M04, RPM1, and RPS2 all encode CNL but are not closely related in sequence; therefore, similar recognition specificities have arisen in different plant lineages, due to convergent evolution to monitor the status of different but potentially related effector targets.

Lettuce is a nonhost species for several bacterial plant pathogens such as members of genera Pseudomonas, Xanthomonas, and Ralstonia that present serious threats to other crops. Effectors of these pathogens are frequently recognized by multiple lettuce accessions, pointing to the involvement of ETI in nonhost resistance to these pathogens (Wroblewski et al. 2009). One or more CNL receptors that recognize these effectors and that confer two resistance specificities to B. lactucae for which lettuce is a ubiquitous host are coded by one or more members of the same NLR family and possess sufficient sequence identity to be silenced by the same RNAi trigger. A possible explanation for this is that effectors of this oomycete and bacterial pathogen share one or more common targets in lettuce, as similarly shown in Arabidopsis (Mukhtar et al. 2011).

Table 7. Comparison of the putative RNAi targets in cv. Salinas of the three constructs targeting members of the $R G C 12$ family that map to the major resistance clusters on chromosome 4 (MRC4)

\begin{tabular}{|c|c|c|c|c|c|c|}
\hline NLR family ${ }^{a}$ & Distanceb $^{b}$ & Genes & CLSS6596_TIR_RNAic & CLSM18700_LRR_RNAi & CLSX586_NB_RNAi & Expression $^{\mathrm{d}}$ \\
\hline$R G C 12$ & 0 & Lsa007832.3 & $\mathrm{T}$ & NT & $\mathrm{T}$ & Yes \\
\hline$R G C 26$ & $2,024,398$ & Lsa031413.1 & NT & NT & NT & Yes \\
\hline$R G C 12$ & $4,523,033$ & Lsa000178.1 & NT & NT & $\mathrm{T}$ & No \\
\hline$R G C 12$ & 25,520 & Lsa000182.1 & $\mathrm{T}$ & $\mathrm{T}$ & $\mathrm{T}$ & Yes \\
\hline$R G C 12$ & 84,080 & Lsa000189.1 & $\mathrm{T}$ & NT & $\mathrm{T}$ & Yes \\
\hline not assigned & 41,836 & Lsa061949.1 & $\mathrm{T}$ & NT & NT & No \\
\hline$R G C 12$ & 33,635 & Lsa061952.1 & NT & NT & $\mathrm{T}$ & No \\
\hline$R G C 12$ & 427,869 & Lsa001301.1 & $\mathrm{T}$ & $\mathrm{T}$ & $\mathrm{T}$ & No \\
\hline$R G C 12$ & 17,510 & Lsa001299.1 & $\mathrm{T}$ & NT & $\mathrm{T}$ & Yes \\
\hline$R G C 12$ & 228,217 & Lsa034545.1 & $\mathrm{T}$ & NT & $\mathrm{T}$ & No \\
\hline$R G C 12$ & 97,334 & Lsa025738.1 & $\mathrm{T}$ & $\mathrm{T}$ & $\mathrm{T}$ & Yes \\
\hline$R G C 12$ & 22,308 & Lsa025736.1 & $\mathrm{T}$ & $\mathrm{T}$ & $\mathrm{T}$ & Yes \\
\hline$R G C 12$ & $4,982,736$ & Lsa011780.1 & NT & $\mathrm{T}$ & $\mathrm{T}$ & Yes \\
\hline$R G C 12$ & 2,401 & Lsa011787.1 & $\mathrm{T}$ & $\mathrm{T}$ & $\mathrm{T}$ & Yes \\
\hline$R G C 12$ & 80,345 & Lsa011782.1 & $\mathrm{T}$ & NT & $\mathrm{T}$ & No \\
\hline$R G C 12$ & 74,149 & Lsa011778.1 & NT & $\mathrm{T}$ & NT & Yes \\
\hline$R G C 12$ & 69,620 & Lsa011781.1 & $\mathrm{T}$ & NT & NT & No \\
\hline$R G C 12$ & 202,442 & Lsa011784.1 & NT & $\mathrm{T}$ & NT & No \\
\hline$R G C 12$ & 6,896 & Lsa011786.1 & $\mathrm{T}$ & $\mathrm{T}$ & $\mathrm{T}$ & Yes \\
\hline$R G C 12$ & 28,154 & Lsa011789.1 & $\mathrm{T}$ & $\mathrm{T}$ & $\mathrm{T}$ & No \\
\hline not assigned & $5,576,688$ & Lsa014503.1 & $\mathrm{T}$ & NT & NT & No \\
\hline$R G C 2$ & $5,740,152$ & Lsa039323.1 & NT & NT & NT & No \\
\hline$R G C 32$ & $38,296,157$ & Lsa038073.1 & NT & NT & NT & Yes \\
\hline
\end{tabular}




\section{Future directions.}

Cloning of resistance genes is of major importance for both applied and basic research purposes. The causal sequences can be used for the development of molecular markers that will never recombine away from the phenotype. Such markers can facilitate marker-assisted selection and allow for pyramiding resistance specificities, particularly when pathogenicity tests are challenging or destructive for the breeding lines. Cloning of individual genes is also a prerequisite for deployment of transgenic cassettes that pyramid resistance genes and will be inherited as a single Mendelian unit, simplifying deployment of multiple resistance genes and leading to more durable disease resistance (Michelmore et al. 2013).

Identifying multiple $R$ genes will enable functional studies to determine the mechanisms that lead to pathogen recognition. A large number of bacterial effectors have been cloned to date (Boch and Bonas 2010; Chang et al. 2005; Lindeberg et al. 2006; Vinatzer et al. 2005) and significant progress has been made in understanding the molecular mechanisms employed by these effectors in both compatible and incompatible interactions (Chisholm et al. 2006; Gimenez-Ibanez et al. 2014; Mudgett 2005; Vinatzer et al. 2006). There are an increasing number of studies on fungal and oomycete effectors and their function (Bozkurt et al. 2012; de Jonge et al. 2011; De Wit et al. 2009; Wang et al. 2011). However, relatively few of their cognate resistance genes have been cloned and studied in detail. Having more cloned $R$ genes will determine how often recognition of pathogen effectors involves direct recognition by an NLR or is indirect due to the NLR guarding a host protein and what downstream pathways are triggered to elicit the defense responses.

\section{MATERIALS AND METHODS}

\section{Plant materials and DNA isolation and sequencing.}

Wild type and mutant lettuce accessions generated previously (Anderson et al. 1996; Okubara et al. 1994) were acquired from the University of California Davis seed collection. DNA isolations were performed on leaf tissue using a modified cetyltrimethylammonium bromide protocol (Bernatzky and Tanksley 1986).

All DNA amplifications were performed using iProof polymerase as per manufacturer's guidelines (Bio-Rad Laboratories, Hercules, CA, U.S.A.) or Phusion HF polymerase (New England Biolabs Inc., Beverly, MA, U.S.A.). Exonuclease I and shrimp alkaline phosphatase (USB Corporation, Cleveland) were used to remove unincorporated oligonucleotides from the PCR products. Sanger sequencing was carried out at the Davis Sequencing Facility (Davis, CA, U.S.A.) or the Plant-Microbe Genomics Facility at The Ohio State University (Columbus, OH, U.S.A.).

The presence of the transgene was confirmed by PCR using the TransgeneF and TransgeneR primers that amplify an 800-bp fragment of the RNAi vector, containing one arm of the inverted repeats. The primers Le9005 L and $\mathrm{R}$ were used as a control to validate genomic PCR amplifications in progeny segregating for the transgene (Fig. 2; Supplementary Table S2).

\section{Generating and evaluating the RNAi transgenics for MRC1 and MRC4.}

Stable RNAi transgenic lines were generated for putative NLR-encoding genes identified as EST-derived markers that mapped within MRC1 and MRC4 (Table 4). A 400- to 500-bp fragment of each candidate gene was cloned as an inverted repeat contiguous with a 300-bp fragment of the GUS reporter gene into the pGollum vector as described previously (Wroblewski et al. 2007). The RNAi constructs were introduced into $A$. tumefaciens
LBA4404 (Hoekema et al. 1983) and were stably transformed into one or more of the cvs. Cobham Green, Diana, or Ninja (Ralph Pearson Transformation Facility at the University of California Davis). On average 12 primary $\left(T_{1}\right)$ RNAi transgenic lines were generated and evaluated for each RNAi construct.

Efficacy of the silencing construct was evaluated in each transgenic line, progeny, and hybrid by Agrobacterium-mediated transient expression assays of the reporter gene GUS (Schöb et al. 1997), which is targeted by a GUS fragment in the pGollum vector, as previously described (Wroblewski et al. 2007). Two leaves were treated each time and the GUS assays were repeated at least twice.

\section{Phenotypic evaluation of transgenic $F_{1}$ plants.}

Evaluation of disease resistance. The $\mathrm{T}_{1}$ lines showing a lack of GUS expression, and therefore presumably silenced for the targeted candidate $R$ gene, were selected for crossing to different genotypes in order to introduce the transgene to a genetic background carrying the corresponding resistance specificity (Table 4). The $T_{1}, T_{2}$, and $F_{1}$ plants were tested for one or both resistance to downy mildew or HR elicited by effectors. Two or three independent transgenic lines, each silenced for $G U S$, were selected as pollen donors for each construct. The $F_{1}$ and $T_{2}$ (for transgenic lines in the Diana and Ninja background) progeny were tested both for phenotypic expression of the resistance gene and for the occurrence of RNAi. Fifteen $F_{1}$ or $T_{2}$ seeds from each cross were germinated in plastic boxes with Hewitt's nutrient solution (Hewitt 1952). Detached cotyledons were inoculated with the appropriate diagnostic isolates of B. lactucae to assay the targeted resistances (Table 4) as previously described (Wroblewski et al. 2007). The disease assay was repeated on leaf discs at the four- to six-leaf stages, using the same protocol. $F_{1}$ progeny derived from the Diana $\times$ siCobham Green-CLSX586_NB cross or $T_{2}$ progeny from siDianaQGF20G21_LRR were additionally tested for abrogation of unlinked resistance genes (Table 4).

Testing for HR phenotype to bacterial effectors. For RNAi constructs targeting genes in MRC1, $\mathrm{T}_{2}$ plants from siNinja or $F_{1}$ plants of Ninja $\times$ siCobham Green were infiltrated with A. tumefaciens $\mathrm{C} 58 \mathrm{C} 1$ strains expressing four bacterial effectors (AvrB, AvrRpm1, AvrRpt1, and AvrPto). Infiltrations with the C58C1 strains harboring the AvrPto effector was used as a positive control for the hypersensitive reaction and harboring the PTFS40 vector expressing the GUS gene as the negative control. Infiltration assays were carried out with the strains harboring the five different constructs on two leaves at the four- to six-leaf stage. The infiltrations were repeated 4 to 5 days later. All infiltrations were carried out as described for GUS assays.

\section{Identification of a full length candidate gene from wild-type Diana.}

The cDNA clone CLSX586 (candidate for $D m 7$, henceforth referred to as $R G C 12 G$ ) was obtained from the lettuce EST collection archived at the Arizona Genomics Institute (Tucson, AZ, U.S.A.) and the 2-kb insert representing the $3^{\prime}$ end of the cDNA was sequenced using M13 forward and M13 reverse oligonucleotide primers. Analysis of $R G C 12 G$ was initiated prior to the release of the lettuce genome sequence. Thus, in order to obtain additional sequence of $R G C 12 G$, a series of nested PCR amplifications were carried out, which utilized 5' degenerate oligonucleotide primers designed to the conserved P-loop motif of the NB domain or $5^{\prime}$ oligonucleotide primers designed to an EST with high sequence identity to $R G C 12 G$ along with a $R G C 12 G$-specific $3^{\prime}$ oligonucleotide primer. Genome walking was carried out to obtain the remaining $5^{\prime}$ sequence of $R G C 12 G$ (PT3042-1; Clontech Laboratories, Inc, Palo Alto, CA, U.S.A.). 


\section{Southern hybridizations.}

High-molecular weight genomic DNA (18 $\mu \mathrm{g})$ was isolated from wild-type cv. Diana and $d m 7$ loss-of-resistance mutant lines and was subsequently digested with restriction enzymes EcoRI, HinDIII, and EcoRV (New England Biolabs, Inc.), following the manufacturer's guidelines. Digested fragments were separated overnight on $0.8 \%$ agarose gels at $40 \mathrm{~V}$. Gels were incubated in $0.25 \mathrm{M} \mathrm{HCl}$ to nick the DNA and were transferred on Hybond $\mathrm{N}^{+}$membrane with an alkaline transfer buffer (GE Healthcare, Piscataway, NJ, U.S.A.). Probe sequences were generated by PCR amplification from the $R G C 12 G$ partial cDNA clones acquired from the Arizona Genomics Institute. PCR products were labeled with dCTP-P $\mathrm{P}^{32}$ using the Random Hexamer labeling kit as per manufacturer's instructions (Invitrogen, San Diego, CA, U.S.A.). Membranes containing the digests of genomic DNA were prehybridized for $4 \mathrm{~h}$ at $65^{\circ} \mathrm{C}$ and were hybridized with the probes for $16 \mathrm{~h}$ at $65^{\circ} \mathrm{C}$. Washes were done at $65^{\circ} \mathrm{C}$ with $6 \times$ saline $\mathrm{SSC}(1 \times \mathrm{SSC}$ is $0.15 \mathrm{M} \mathrm{NaCl}$ plus $0.015 \mathrm{M}$ sodium citrate) and $6 \%$ sodium dodecyl sulfate (SDS) for $30 \mathrm{~min}, 2 \times \mathrm{SSC}$ and $2 \%$ SDS for $10 \mathrm{~min}, 0.5 \times$ SSC and $0.5 \%$ SDS for $10 \mathrm{~min}$. Membranes were visualized after hybridization using the Storm Phosphorimager (Amersham Pharmacia Biosciences, Piscataway, NJ, U.S.A.).

\section{Identification of potential targets of RNAi constructs.}

BLAST searches using stringent parameters were conducted to identify genes potentially silenced by each of the RNAi constructs used in this study. At least one stretch of $21 \mathrm{nt}$ with $100 \%$ identity to the trigger sequence is required for a gene to classify it as a potential target. Targets were identified for RNAi constructs of $R G C l$ family members that abrogated resistance specificities in the genotypes whose genome sequence was available, i.e., L. sativa cvs. Salinas, Diana, and Valmaine. RNAi targets were also identified for $R G C 12$ constructs in cv. Salinas.

\section{Identification of homologous NLR-encoding genes of MRC1 and MRC4 in three additional genotypes.}

The genome assemblies of cvs. Diana, Valmaine, and L. serriola accession US96UC23 were mined for the presence or absence and level of sequence diversity of NLR-encoding genes within each MRC. Presence was confirmed with best reciprocal blast hits with $>89 \%$ sequence identity, across the entire length of each coding sequence.

\section{Gene expression of NLR-encoding genes in MRC1 and MRC4.}

The reads used to generate the lettuce reference transcriptome (cv. Salinas) (Matvienko et al. 2013) was used qualitatively to assess evidence of transcription for the NLRencoding genes in MRC1 and MRC2. The raw reads were mapped back to pseudomolecules consisting of 385 NLRencoding genes using CLC Genomics Workbench 7.0.3 (CLC bio website). The mapping parameters used were: mismatch cost $=2$, insertion and deletion cost $=3$, minimum length fraction $=0.9$, and similarity 1 . A small number of nonuniquely mapped reads was tolerated given the high sequence similarity among members of the same family, but at least $70 \%$ of the reads mapped uniquely to each gene. A minimum of threefold coverage for the entire length of the gene was required for sufficient evidence of transcription.

\section{ACKNOWLEDGMENTS}

We thank A. Gutek, D. Lavelle, J. Nam, O. Ochoa, P. Sanders, B. Seminatore, A. Turnquist, and R. Walker for technical assistance. This research was supported by grants numbers 04-35300-14601 and 200535300-004447 from the National Research Initiative Plant Genome Program of the United States Department of Agriculture Cooperative State
Research, Education and Extension Service and DBI0421630 and DBI0211923 from the Plant Genome Research Program of the National Science Foundation.

\section{LITERATURE CITED}

Anderson, P. A., Okubara, P. A., Arroyo-Garcia, R., Meyers, B. C., and Michelmore, R. W. 1996. Molecular analysis of irradiation-induced and spontaneous deletion mutants at a disease resistance locus in Lactuca sativa. Mol. Gen. Genet. 251:316-325.

Ashfield, T., Ong, L. E., Nobuta, K., Schneider, C. M., and Innes, R. W. 2004. Convergent evolution of disease resistance gene specificity in two flowering plant families. Plant Cell 16:309-318.

Axtell, M. J., and Staskawicz, B. J. 2003. Initiation of RPS2-specified disease resistance in Arabidopsis is coupled to the AvrRpt2-directed elimination of RIN4. Cell 112:369-377.

Bernatzky, R., and Tanksley, S. D. 1986. Toward a saturated linkage map in tomato based on isozymes and random cDNA sequences. Genetics 112: 887-898.

Boch, J., and Bonas, U. 2010. Xanthomonas AvrBs3 family-type III effectors: discovery and function. Annu. Rev. Phytopathol. 48:419-436.

Boller, T., and Felix, G. 2009. A renaissance of elicitors: Perception of microbe-associated molecular patterns and danger signals by patternrecognition receptors. Pages 379-406 in: Annual Review of Plant Biology Annual Reviews, Palo Alto.

Borhan, M. H., Gunn, N., Cooper, A., Gulden, S., Tör, M., Rimmer, S. R., and Holub, E. B. 2008. WRR4 encodes a TIR-NB-LRR protein that confers broad-spectrum white rust resistance in Arabidopsis thaliana to four physiological races of Albugo candida. Mol. Plant Microbe Interact. 21:757-768.

Botella, M. A., Parker, J. E., Frost, L. N., Bittner-Eddy, P. D., Beynon, J. L., Daniels, M. J., Holub, E. B., and Jones, J. D. G. 1998. Three genes of the Arabidopsis RPP1 complex resistance locus recognize distinct Peronospora parasitica avirulence determinants. Plant Cell 10:1847-1860.

Bozkurt, T. O., Schornack, S., Banfield, M. J., and Kamoun, S. 2012. Oomycetes, effectors, and all that jazz. Curr. Opin. Plant Biol. 15:483-492.

Chang, J. H., Urbach, J. M., Law, T. F., Arnold, L. W., Hu, A., Gombar, S., Grant, S. R., Ausubel, F. M., and Dangl, J. L. 2005. A high-throughput, near-saturating screen for type III effector genes from Pseudomonas syringae. Proc. Natl. Acad. Sci. U.S.A. 102:2549-2554.

Chen, N. W., Sévignac, M., Thareau, V., Magdelenat, G., David, P., Ashfield, T., Innes, R. W., and Geffroy, V. 2010. Specific resistances against Pseudomonas syringae effectors AvrB and AvrRpm1 have evolved differently in common bean (Phaseolus vulgaris), soybean (Glycine max), and Arabidopsis thaliana. New Phytol. 187:941-956.

Chin, D. B., Arroyo-Garcia, R., Ochoa, O. E., Kesseli, R. V., Lavelle, D. O., and Michelmore, R. W. 2001. Recombination and spontaneous mutation at the major cluster of resistance genes in lettuce (Lactuca sativa). Genetics 157:831-849.

Chisholm, S. T., Coaker, G., Day, B., and Staskawicz, B. J. 2006. Hostmicrobe interactions: Shaping the evolution of the plant immune response. Cell 124:803-814.

Crute, I. R. 1989. Lettuce downy mildew: A case study in integrated control. Page 30-53 in: Plant Disease Epidemiology. K. J. Leonard and W. E. Fry, eds. McGraw-Hill, New York.

Crute, I. 1992. The role of resistance breeding in the intergrated control of downy mildew (Bremia lactucae) in protected lettuce. Euphytica 63: 95-102.

Crute, I., and Johnson, A. 1976. The genetic relationship between races of Bremiae lactucae and cultivars of Lactuca sativa. Ann. Appl. Biol. 83: 125-137.

Davis, R. M., Subbarao, K. V., Raid, R. N., and Kurtz, E. A. 1997. Compendium of lettuce diseases. APS Press, St. Paul, MN, U.S.A.

de Jonge, R., Bolton, M. D., and Thomma, B. P. H. J. 2011. How filamentous pathogens co-opt plants: The ins and outs of fungal effectors. Curr. Opin. Plant Biol. 14:400-406.

De Wit, P. J., Mehrabi, R., Van den Burg, H. A., and Stergiopoulos, I. 2009. Fungal effector proteins: Past, present and future. Mol. Plant Pathol. 10: 735-747.

Desveaux, D., Singer, A. U., Wu, A.-J., McNulty, B. C., Musselwhite, L., Nimchuk, Z., Sondek, J., and Dangl, J. L. 2007. Type III effector activation via nucleotide binding, phosphorylation, and host target interaction. PLoS Pathog. 3:e48.

Dodds, P. N., and Rathjen, J. P. 2010. Plant immunity: Towards an integrated view of plant-pathogen interactions. Nat. Rev. Genet. 11:539-548.

Ellis, P., McClement, S., Saw, P., Phelps, K., Vice, W., Kift, N., Astley, D., and Pink, D. 2002. Identification of sources of resistance in lettuce to the lettuce root aphid, Pemphigus bursarius. Euphytica 125:305-315. 
Farrara, B. F., Ilott, T. W., and Michelmore, R. W. 1987. Genetic analysis of factors for resistance to downy mildew (Bremia lactucae) in species of lettuce (Lactuca sativa and L. serriola). Plant Pathol. 36:499-514.

Feng, F., and Zhou, J. M. 2012. Plant-bacterial pathogen interactions mediated by type III effectors. Curr. Opin. Plant Biol. 15:469-476.

Finn, R. D., Mistry, J., Schuster-Böckler, B., Griffiths-Jones, S., Hollich, V., Lassmann, T., Moxon, S., Marshall, M., Khanna, A., Durbin, R., Eddy, S. R., Sonnhammer, E. L., and Bateman, A. 2006. Pfam: Clans, web tools and services. Nucleic Acids Res. 34:D247-D251.

Gasteiger, E., Gattiker, A., Hoogland, C., Ivanyi, I., Appel, R. D., and Bairoch, A. 2003. ExPASy: The proteomics server for in-depth protein knowledge and analysis. Nucleic Acids Res. 31:3784-3788.

Gimenez-Ibanez, S., Boter, M., Fernández-Barbero, G., Chini, A., Rathjen, J. P., and Solano, R. 2014. The bacterial effector HopX1 targets JAZ transcriptional repressors to activate jasmonate signaling and promote infection in Arabidopsis. PLoS Biol. 12:e1001792.

Głowacki, S., Macioszek, V. K., and Kononowicz, A. K. 2011. R proteins as fundamentals of plant innate immunity. Cell. Mol. Biol. Lett. 16:1-24.

Guo, Y. L., Fitz, J., Schneeberger, K., Ossowski, S., Cao, J., and Weigel, D. 2011. Genome-wide comparison of nucleotide-binding site-leucine-rich repeat-encoding genes in Arabidopsis. Plant Physiol. 157:757-769.

Hewitt, E. J. 1952. Sand and Water Culture Methods Used in the Study of Plant Nutrition. Farnham Royal, Commonwealth Agricultural Bureaux, Bucks, England.

Hoekema, A., Hirsch, P. R., Hooykaas, P. J. J., and Schilperoort, R. A. 1983. A binary plant vector strategy based on separation of vir-region and T-region of the agrobacterium-tumefaciens Ti-plasmid. Nature 303: 179-180.

Hulbert, S. H., and Michelmore, R. W. 1985. Linkage analysis of genes for resistance to downy mildew (Bremia lactucae) in lettuce (Lactuca sativa). Theor. Appl. Genet. 70:520-528.

Ilott, T., Hulbert, S., and Michelmore, R. 1989. Genetic analysis of the gene-for-gene interaction between lettuce (Lactuca sativa) and Bremia lactucae. Phytopathology 79:888-897.

Jebanathirajah, J. A., Peri, S., and Pandey, A. 2002. Toll and interleukin-1 receptor (TIR) domain-containing proteins in plants: A genomic perspective. Trends Plant Sci. 7:388-391.

Jeuken, M., and Lindhout, P. 2002. Lactuca saligna, a non-host for lettuce downy mildew (Bremia lactucae), harbors a new race-specific Dm gene and three QTLs for resistance. Theor. Appl. Genet. 105:384-391.

Jeuken, M. J., Zhang, N. W., McHale, L. K., Pelgrom, K., den Boer, E., Lindhout, P., Michelmore, R. W., Visser, R. G., and Niks, R. E. 2009. Rin4 causes hybrid necrosis and race-specific resistance in an interspecific lettuce hybrid. Plant Cell 21:3368-3378.

Jones, J. D., and Dangl, J. L. 2006. The plant immune system. Nature 444: 323-329.

Katagiri, F., and Tsuda, K. 2010. Understanding the plant immune system. Mol. Plant Microbe Interact. 23:1531-1536.

Kuang, H., Woo, S.-S., Meyers, B. C., Nevo, E., and Michelmore, R. W. 2004. Multiple genetic processes result in heterogeneous rates of evolution within the major cluster disease resistance genes in lettuce. Plant Cell 16:2870-2894.

Landry, B. S., Kesseli, R. V., Farrara, B., and Michelmore, R. W. 1987. A genetic map of lettuce (Lactuca sativa L.) with restriction fragment length polymorphism, isozyme, disease resistance and morphological markers. Genetics 116:331-337.

Lindeberg, M., Cartinhour, S., Myers, C. R., Schechter, L. M., Schneider, D. J., and Collmer, A. 2006. Closing the circle on the discovery of genes encoding Hrp regulon members and type III secretion system effectors in the genomes of three model Pseudomonas syringae strains. Mol. Plant Microbe Interact. 19:1151-1158.

Liu, J., Liu, X., Dai, L., and Wang, G. 2007. Recent progress in elucidating the structure, function and evolution of disease resistance genes in plants. J. Genet. Genomics 34:765-776.

Lukasik, E., and Takken, F. L. W. 2009. STANDing strong, resistance proteins instigators of plant defence. Curr. Opin. Plant Biol. 12:427-436.

Mackey, D., Holt, B. F., 3rd, Wiig, A., and Dangl, J. L. 2002. RIN4 interacts with Pseudomonas syringae type III effector molecules and is required for RPM1-mediated resistance in Arabidopsis. Cell 108:743-754.

Mackey, D., Belkhadir, Y., Alonso, J. M., Ecker, J. R., and Dangl, J. L. 2003. Arabidopsis RIN4 is a target of the type III virulence effector AvrRpt2 and modulates RPS2-mediated resistance. Cell 112:379-389.

Maisonneuve, B., Bellec, Y., Anderson, P., and Michelmore, R. W. 1994 Rapid mapping of two genes for resistance to downy mildew from Lactuca serriola to existing clusters of resistance genes. Theor. Appl. Genet. 89:96-104.

Matvienko, M., Kozik, A., Froenicke, L., Lavelle, D., Martineau, B., Perroud, B., and Michelmore, R. 2013. Consequences of normalizing transcriptomic and genomic libraries of plant genomes using a duplexspecific nuclease and tetramethylammonium chloride. PLoS ONE 8 : e55913.

McHale, L., Tan, X., Koehl, P., and Michelmore, R. W. 2006. Plant NBSLRR proteins: Adaptable guards. Genome Biol. 7:212.

McHale, L. K., Truco, M. J., Kozik, A., Wroblewski, T., Ochoa, O. E., Lahre, K. A., Knapp, S. J., and Michelmore, R. W. 2009. The genomic architecture of disease resistance in lettuce. Theor. Appl. Genet. 118: 565-580.

Meyers, B. C., Chin, D. B., Shen, K. A., Sivaramakrishnan, S., Lavelle, D. O., Zhang, Z., and Michelmore, R. W. 1998. The major resistance gene cluster in lettuce is highly duplicated and spans several megabases. Plant Cell 10:1817-1832.

Meyers, B. C., Kozik, A., Griego, A., Kuang, H., and Michelmore, R. W. 2003. Genome-wide analysis of NBS-LRR-encoding genes in Arabidopsis. Plant Cell 15:809-834.

Michelmore, R. W., Christopoulou, M., and Caldwell, K. S. 2013. Impacts of resistance gene genetics, function, and evolution on a durable future. Annu. Rev. Phytopathol. 51:291-319.

Michelmore, R. W., and Meyers, B. C. 1998. Clusters of resistance genes in plants evolve by divergent selection and a birth-and-death process Genome Res. 8:1113-1130.

Michelmore, R., Ochoa, O., and Wong, J. 2009. Bremia lactucae and lettuce downy mildew. Pages 241-262 in: Oomycete Genetics and Genomics: Diversity, Plant and Animal Interactions, and Toolbox. S. Kamoun and K. Lamour, eds. John Wiley \& Sons, Hoboken, NJ, U.S.A.

Michelmore, R. W., Truco, M. J., and Ochoa, O. E. 2010. Breeding Crisphead and Leafy Lettuce. California Leafy Greens Research Program, Salinas, CA, U.S.A. http://calgreens.org/control/uploads/ Michelmore_Breeding_Crisphead_and_Leafy_Lettuce.pdf. Published online.

Michelmore, R., and Wong, J. 2008. Classical and molecular genetics of Bremia lactucae, cause of lettuce downy mildew. Eur. J. Plant Pathol. 122:19-30.

Monaghan, J., and Zipfel, C. 2012. Plant pattern recognition receptor complexes at the plasma membrane. Curr. Opin. Plant Biol. 15:349-357.

Mondragón-Palomino, M., Meyers, B. C., Michelmore, R. W., and Gaut, B. S. 2002. Patterns of positive selection in the complete NBS-LRR gene family of Arabidopsis thaliana. Genome Res. 12:1305-1315.

Mudgett, M. B. 2005. New insights to the function of phytopathogenic bacterial type III effectors in plants. Annu. Rev. Plant Biol. 56:509-531.

Mukhtar, M. S., Carvunis, A.-R., Dreze, M., Epple, P., Steinbrenner, J., Moore, J., Tasan, M., Galli, M., Hao, T., Nishimura, M. T., Pevzner, S. J., Donovan, S. E., Ghamsari, L., Santhanam, B., Romero, V., Poulin, M. M., Gebreab, F., Gutierrez, B. J., Tam, S., Monachello, D., Boxem, M., Harbort, C. J., McDonald, N., Gai, L., Chen, H., He, Y., European Union Effectoromics Consortium, Vandenhaute, J., Roth, F. P., Hill, D. E., Ecker, J. R., Vidal, M., Beynon, J., Braun, P., and Dangl, J. L.; European Union Effectoromics Consortium. 2011. Independently evolved virulence effectors converge onto hubs in a plant immune system network. Science 333:596-601.

Nandety, R. S., Caplan, J. L., Cavanaugh, K., Perroud, B., Wroblewski, T., Michelmore, R. W., and Meyers, B. C. 2013. The role of TIR-NBS and TIR-X proteins in plant basal defense responses. Plant Physiol. 162: 1459-1472.

National Agricultural Statistical Service. 2013. Vegetables Annual Summary. United States Department of Agreculture, Washington, D.C Published online.

Nicaise, V., German-Retana, S., Sanjuán, R., Dubrana, M.-P., Mazier, M., Maisonneuve, B., Candresse, T., Caranta, C., and LeGall, O. 2003. The eukaryotic translation initiation factor $4 \mathrm{E}$ controls lettuce susceptibility to the potyvirus Lettuce mosaic virus. Plant Physiol. 132:1272-1282.

Okubara, P. A., Anderson, P. A., Ochoa, O. E., and Michelmore, R. W. 1994. Mutants of downy mildew resistance in Lactuca sativa (lettuce). Genetics 137:867-874.

Qi, D., DeYoung, B. J., and Innes, R. W. 2012. Structure-function analysis of the coiled-coil and leucine-rich repeat domains of the RPS5 disease resistance protein. Plant Physiol. 158:1819-1832.

Rafiqi, M., Ellis, J. G., Ludowici, V. A., Hardham, A. R., and Dodds, P. N. 2012. Challenges and progress towards understanding the role of effectors in plant-fungal interactions. Curr. Opin. Plant Biol. 15:477-482.

Robbins, M. A., Witsenboer, H., Michelmore, R. W., Laliberte, J. F., and Fortin, M. G. 1994. Genetic mapping of turnip mosaic virus resistance in Lactuca sativa. Theor. Appl. Genet. 89:583-589.

Schöb, H., Kunz, C., and Meins, F., Jr. 1997. Silencing of transgenes introduced into leaves by agroinfiltration: A simple, rapid method for investigating sequence requirements for gene silencing. Mol. Gen Genet. 256:581-585. 
Sharma, T. R., Das, A., Kumar, S. P., and Lodha, M. L. 2009. Resistance gene analogues as a tool for rapid identification and cloning of disease resistance genes in plants-A review. J. Plant Biochem. Biotechnol. 18:1-11.

Shen, K. A., Chin, D. B., Arroyo-Garcia, R., Ochoa, O. E., Lavelle, D. O., Wroblewski, T., Meyers, B. C., and Michelmore, R. W. 2002. Dm3 is one member of a large constitutively expressed family of nucleotide binding siteleucine-rich repeat encoding genes. Mol. Plant Microbe Interact. 15:251-261.

Takken, F. L. W., and Goverse, A. 2012. How to build a pathogen detector: Structural basis of NB-LRR function. Curr. Opin. Plant Biol. 15: 375-384.

Tameling, W. I. L., and Takken, F. L. W. 2008. Resistance proteins: Scouts of the plant innate immune system. Eur. J. Plant Pathol. 121:243-255.

Tamura, M., and Tachida, H. 2011. Evolution of the number of LRRs in plant disease resistance genes. Mol. Genet. Genomics 285:393-402.

Truco, M. J., Antonise, R., Lavelle, D., Ochoa, O., Kozik, A., Witsenboer, H., Fort, S. B., Jeuken, M. J., Kesseli, R. V., Lindhout, P., Michelmore, R. W., and Peleman, J. 2007. A high-density, integrated genetic linkage map of lettuce (Lactuca spp.). Theor. Appl. Genet. 115:735-746.

Truco, M. J., Ashrafi, H., Kozik, A., van Leeuwen, H., Bowers, J., ReyesChin Wo, S., Stoffel, K., Xu, H., Hill, T., Van Deynze, A., and Michelmore, R. W. 2013. An ultra high-density, transcript-based, genetic map of lettuce. G3 3:617-631.

Van Der Biezen, E. A., Freddie, C. T., Kahn, K., Parker, J. E., and Jones, J. D. 2002. Arabidopsis RPP4 is a member of the RPP5 multigene family of TIR-NB-LRR genes and confers downy mildew resistance through multiple signalling components. Plant J. 29:439-451.

Vinatzer, B. A., Jelenska, J., and Greenberg, J. T. 2005. Bioinformatics correctly identifies many type III secretion substrates in the plant pathogen Pseudomonas syringae and the biocontrol isolate P. fluorescens SBW25. Mol. Plant Microbe Interact. 18:877-888.

Vinatzer, B. A., Teitzel, G. M., Lee, M. W., Jelenska, J., Hotton, S., Fairfax, K., Jenrette, J., and Greenberg, J. T. 2006. The type III effector repertoire of Pseudomonas syringae pv. syringae B728a and its role in survival and disease on host and non-host plants. Mol. Microbiol. 62:26-44.

Wang, Q., Han, C., Ferreira, A. O., Yu, X., Ye, W., Tripathy, S., Kale, S. D., Gu, B., Sheng, Y., Sui, Y., Wang, X., Zhang, Z., Cheng, B., Dong, S., Shan, W., Zheng, X., Dou, D., Tyler, B. M., and Wang, Y. 2011 Transcriptional programming and functional interactions within the Phytophthora sojae RXLR effector repertoire. Plant Cell 23:2064-2086.

Whitham, S., Dinesh-Kumar, S. P., Choi, D., Hehl, R., Corr, C., and Baker, B. 1994. The product of the tobacco mosaic virus resistance gene $N$ : Similarity to toll and the interleukin-1 receptor. Cell 78:1101-1115.

Witsenboer, H., Kesseli, R. V., Fortin, M. G., Stanghellini, M., and Michelmore, R. W. 1995. Sources and genetic structure of a cluster of genes for resistance to three pathogens in lettuce. Theor. Appl. Genet. 91:178-188.

Wroblewski, T., Piskurewicz, U., Tomczak, A., Ochoa, O., and Michelmore, R. W. 2007. Silencing of the major family of NBS-LRR-encoding genes in lettuce results in the loss of multiple resistance specificities. Plant $\mathrm{J}$. 51:803-818.

Wroblewski, T., Caldwell, K. S., Piskurewicz, U., Cavanaugh, K. A., Xu, H., Kozik, A., Ochoa, O., McHale, L. K., Lahre, K., Jelenska, J., Castillo, J. A., Blumenthal, D., Vinatzer, B. A., Greenberg, J. T., and Michelmore, R. W. 2009. Comparative large-scale analysis of interactions between several crop species and the effector repertoires from multiple pathovars of Pseudomonas and Ralstonia. Plant Physiol. 150:1733-1749.

Yue, J. X., Meyers, B. C., Chen, J. Q., Tian, D., and Yang, S. 2012. Tracing the origin and evolutionary history of plant nucleotide-binding siteleucine-rich repeat (NBS-LRR) genes. New Phytol. 193:1049-1063.

\section{AUTHOR-RECOMMENDED INTERNET RESOURCES}

CLC bio website: http://www.clcbio.com

Lettuce Genome Resource: https://gr.genomecenter.ucdavis.edu 